\title{
On the value of soil moisture measurements in vadose zone hydrology: A review
}

\author{
H. Vereecken, ${ }^{1}$ J. A. Huisman, ${ }^{1}$ H. Bogena, ${ }^{1}$ J. Vanderborght, ${ }^{1}$ \\ J. A. Vrugt, ${ }^{2}$ and J. W. Hopmans ${ }^{3}$ \\ Received 13 January 2008; revised 29 June 2008; accepted 22 July 2008; published 21 October 2008.
}

[1] We explore and review the value of soil moisture measurements in vadose zone hydrology with a focus on the field and catchment scales. This review is motivated by the increasing ability to measure soil moisture with unprecedented spatial and temporal resolution across scales. We highlight and review the state of the art in using soil moisture measurements for (1) estimation of soil hydraulic properties, (2) quantification of water and energy fluxes, and (3) retrieval of spatial and temporal dynamics of soil moisture profiles. We argue for the urgent need to have access to field monitoring sites and databases that include detailed information about variability of hydrological fluxes and parameters, including their upscaled values. In addition, improved data assimilation methods are needed that fully exploit the information contained in soil moisture data. The development of novel upscaling methods for predicting effective moisture fluxes and disaggregation schemes toward integrating large-scale soil moisture measurements in hydrological models will increase the value of soil moisture measurements. Finally, we recognize a need to develop strategies that combine hydrogeophysical measurement techniques with remote sensing methods.

Citation: Vereecken, H., J. A. Huisman, H. Bogena, J. Vanderborght, J. A. Vrugt, and J. W. Hopmans (2008), On the value of soil moisture measurements in vadose zone hydrology: A review, Water Resour. Res., 44, W00D06, doi:10.1029/2008WR006829.

\section{Introduction}

[2] Soil moisture is a key variable for understanding hydrological processes in the vadose zone. It plays an important role in weather and climate predictions from the regional to the global scale by controlling the exchange and partitioning of water and energy fluxes at the land surface. Agricultural and irrigation management practices, especially in semiarid and arid regions, largely depend on a timely and accurate characterization of temporal and spatial soil moisture dynamics in the root zone because of the impact of soil moisture on the production and health status of crops and salinization. In addition, soil moisture also plays a major role in the organization of natural ecosystems and biodiversity.

[3] Soil moisture studies have mainly focused on the characterization of soil moisture fields at various spatial scales. Reviews on this topic were published by Blöschl and Sivapalan [1995], Mahmood [1996], Sposito [1998], and Western et al. [2002]. We anticipate an increasing availability of soil moisture data in the near future because of the increased use of nondestructive measurement techniques, such as ground penetrating radar [e.g., Eppstein and Dougherty, 1998; Huisman et al., 2001, 2002; Lunt et al.,

\footnotetext{
${ }^{1}$ Agrosphere Institute, ICG-4, Institute of Chemistry and Dynamics of the Geosphere, Forschungszentrum Jülich GmbH, Jülich, Germany.

${ }^{2}$ Center for Nonlinear Studies, Los Alamos National Laboratory, Los Alamos, New Mexico, USA.

${ }^{3}$ Department of Land, Air and Water Resources, University of California, Davis, California, USA.

Copyright 2008 by the American Geophysical Union. 0043-1397/08/2008WR006829
}

2005; Lambot and Gorriti, 2007], soil moisture sensor networks [e.g., Cardell-Oliver et al., 2005] and new remote sensing platforms [e.g., Wagner et al., 2007], such as SMOS [Kerr et al., 2001] and SMAP (http://smap.jpl. nasa.gov). These new methods provide unique opportunities to map the spatial and temporal variation of soil moisture at an unprecedented resolution and with the potential of providing measurement coverage across a range of scales. However, guidance is needed on how to effectively use this increasing wealth of soil moisture data toward advancing the field of vadose zone hydrology. Specifically, in this paper we review and discuss the scientific benefits of improved characterization of spatial and temporal soil moisture dynamics and we review approaches that require information contained in soil moisture measurements to predict hydrological state variables (e.g., soil moisture fields, soil water storage), parameters (e.g., hydraulic properties) and fluxes (e.g., evapotranspiration, groundwater recharge, runoff, and plant water uptake) at the field and catchment scale. We focus on information content rather than on availability and performance of soil moisture measurement techniques, as these have been recently addressed by Robinson et al. [2008].

[4] The integration of observations characterizing the state of a system (e.g., vadose zone moisture content) into models to predict system states is known as data assimilation. It is frequently used in meteorology and climate research [Heathman et al., 2003], and increasingly in hydrology. In the present context, data assimilation can be used to consider soil moisture information from remote and ground sensing to improve model predictions of soil moisture at the scale of interest, and to resolve spatial and 
temporal structure of soil moisture using surrogate information (soil texture and depth, topography). Alternatively, data fusion approaches are applied in the hydrogeophysics field [Hyndman and Gorelick, 1996; Kowalsky et al., 2005; Rubin and Hubbard, 2005; Vereecken et al., 2004, 2006], to optimally merge uncertain model predictions and soil moisture data. In this review, we summarize the different approaches toward improving soil moisture prediction.

[5] The paper is organized in nine sections. In section 2 we will briefly address the approaches used to measure and predict soil water at the field and catchment scale. Data assimilation methods are presented in section 3 . In section 4 , we address the retrieval of high-resolution temporal and spatial soil moisture distributions from locally measured soil moisture data with a special focus on the value of nearsurface soil moisture measurements to retrieve vertical soil moisture profiles. The use of soil moisture data to derive soil hydraulic properties is discussed in section 5. In section 6, we discuss how soil moisture data can be used to derive hydrological fluxes. Section 7 evaluates the potential of soil moisture data and its spatial variability to improve the prediction of surface energy fluxes. The derivation of structural, morphological and other soil properties is discussed in section 8. In section 9, we discuss further research needs.

\section{Methods for Measuring and Modeling Soil Moisture}

\subsection{Overview of Soil Moisture Measurement Techniques}

[6] There is a substantial body of literature describing soil moisture measurement methods [e.g., Evett and Parkin, 2005]. A recent review on advances in sensor technology, in particular in the field of hydrogeophysics and distributed sensor development, is given by Robinson et al. [2008]. They defined two main categories of soil moisture measurements: contact-based and contact-free methods. Contactbased methods require direct contact with the soil. Examples of contact methods include capacitance sensors [e.g., Dean et al., 1987; Bell et al., 1987; Blonquist et al., 2005a, 2005b; Fares and Polyakov, 2006; Bogena et al., 2007], time domain reflectometry [Topp, 2003; Robinson et al., 2003], electrical resistivity measurements [e.g., Goyal et al., 1996; Hymer et al., 2000; Zhou et al., 2001; Michot et al., 2003; Samouelian et al., 2005], heat pulse sensors [Valente et al., 2006], fiber optic sensors [Alessi and Prunty, 1986; Garrido et al., 1999; Fields et al., 2000; Robinson et al., 2008] and destructive sampling (e.g., gravimetric methods). These measurement techniques typically provide spatially and temporally highly resolved measurements at the point scale (e.g., vertical soil moisture profile) and the spatial-temporal dynamics of soil moisture at the field scale. Excellent reviews of each of these methods and discussions on the attainable accuracy are available, and the reader is referred to these papers for further information [e.g., Robinson et al., 2008].

[7] The second category consists of contact free measurement techniques. Remote sensing methods are prominent in this category. Remote sensing methods include passive microwave radiometers [Schmugge et al., 1992; Sellers et al., 1992; Jackson, 1993; Jackson et al., 1992, 1993, 1995,
1999; Laymon et al., 1999; Schmugge et al., 2002; Narayan et al., 2004; Crosson et al., 2005]; synthetic aperture radars [Ulaby et al., 1996; Altese et al., 1996; Verhoest et al., 1998, 2007; Biftu and Gan, 1999; Satalino et al., 2002; Western et al., 2004], scatterometers [Wagner et al., 2003; Ceballos et al., 2005; Verstraeten et al., 2006; Blumberg et al., 2006], and thermal methods [Pratt and Ellyett, 1979; Price, 1980; Gillies and Carlson, 1995; Verstraeten et al., 2006; Katra et al., 2006, 2007; Sugiura et al., 2007]. These methods are either ground based or operated from airborne or spaceborne platforms. A recent overview of the operational readiness of microwave remote sensing of soil moisture content is given by Wagner et al. [2007]. For larger-scale applications, Drusch et al. [2004] provide a comparison between remotely sensed soil moisture data and data obtained from operational products. Key limitations of current remote sensing methods are problems with spatial averaging and a small penetration depth. These limitations make it difficult to obtain accurate values of soil moisture at a much smaller spatial support than the observation, and to sense moisture variations beyond a thin surface layer. To overcome these limitations, disaggregation approaches have been introduced to increase spatial resolution, and radiometer systems (e.g., SMOS) are operated in the $\mathrm{L}$ band to maximize penetration depth [Kerr et al., 2001]. To further increase the efficiency of remote sensing platforms, multifrequency and coupled active systems with larger antennas are promising [Kerr, 2007].

[8] Contact-free hydrogeophysical methods are also increasingly used. The most prominent examples are offground ground penetrating radar [e.g., Huisman et al., 2003; Serbin and Or, 2004, 2005; Lambot et al., 2006a, 2006b] and electromagnetic induction [e.g., Sheets and Hendrickx, 1995; Akbar et al., 2005; Corwin and Lesch, 2005]. Although these methods are suited for occasional mapping, they are not able to provide data on soil moisture with a high temporal resolution at the catchment scale.

[9] Catchment-scale information with a high temporal resolution could be provided by emerging wireless sensor network technologies [e.g., Cardell-Oliver et al., 2005]. There are at least three reasons to use sensors networks in vadose zone hydrology. First, these networks will improve the spatial and temporal coverage of soil moisture measurements. This information may then be used for improved characterization of hydrological fluxes, for calibration and validation of remote sensing data, and for development of upscaling and downscaling techniques. Second, networks are designed to ensure a good data quality from fielddeployed sensors through their communication ability (e.g., online visualization of data). Third, sensor networks improve data continuity through early detection of sensor failures. An important prerequisite for the optimal performance of wireless soil moisture networks is the careful selection of soil moisture probes [e.g., Bogena et al., 2007]. Sensor networks require probes that maximize sensing volume while drawing minimum power [Blonquist et al., 2005a, 2005b; Bogena et al., 2007]. Further work is needed to optimally design these soil moisture networks in terms of measurement frequency and spatial arrangement [Yoo, 2001; Jacobs et al., 2004], and for validation of remote sensing data. To optimize the required number of sensors, the temporal stability of soil moisture patterns [e.g., 


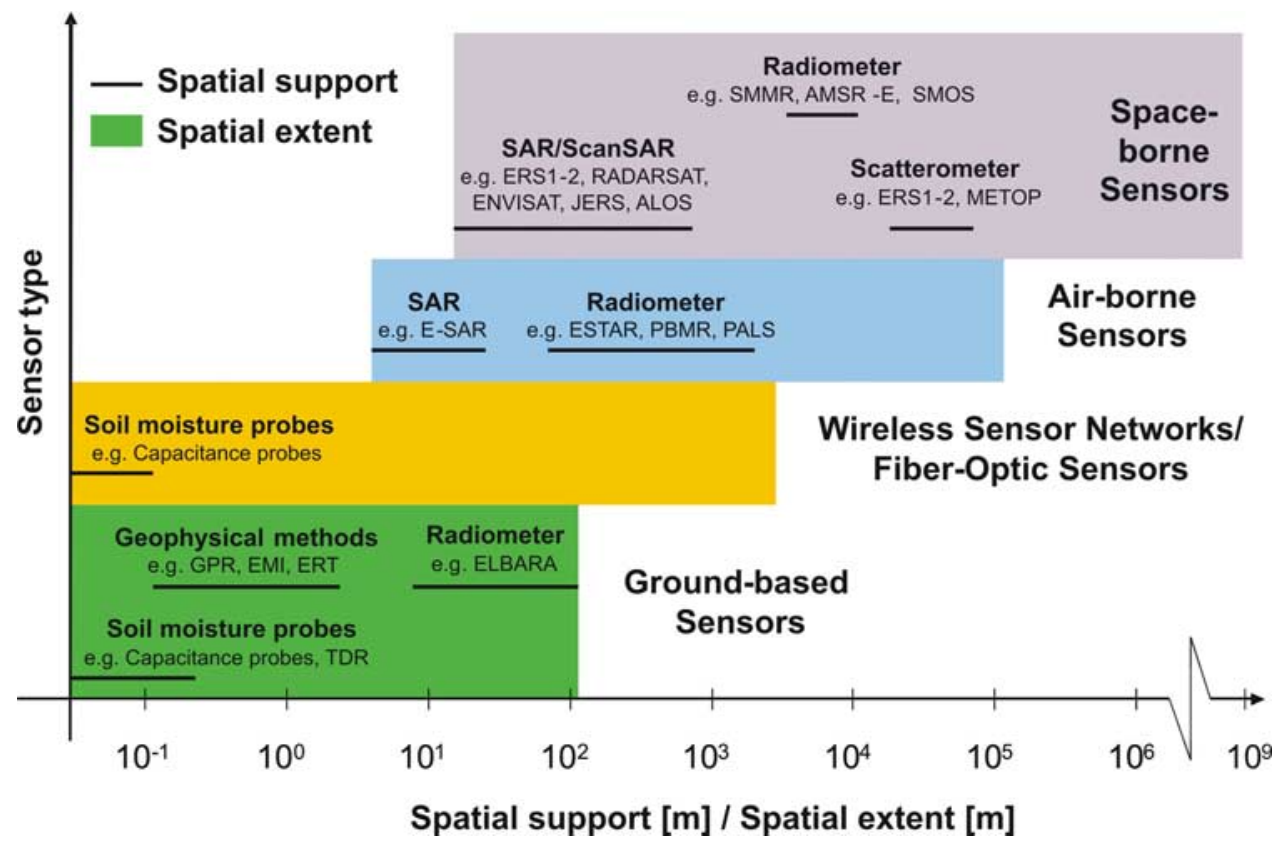

Figure 1. Support scale of soil moisture observations or measurements obtained from ground-based sensors (GPR, ground penetrating radar; TDR, time domain reflectometry; EMI, electromagnetic induction; ELBARA, L band radiometer), wireless sensor networks, airborne sensors (SAR, synthetic aperture radar; E-SAR, experimental airborne SAR; ESTAR, electronically scanned thinned aperture radiometer; PBMR, L band push broom microwave radiometer; PALS, passive and active L/S band sensor), and spaceborne sensors (ALOS, Advanced Land Observing Satellite; AMSR-E, Advanced Microwave Scanning Radiometer; ENVISAT, Environmental Satellite; ERS1-2, European Remote Sensing Satellite 1-2; JERS, Japanese Environmental Remote Sensing; SMOS, Soil Moisture and Ocean Salinity Satellite; SMMR, Scanning Multichannel Microwave).

Vachaud et al., 1985; Jacobs et al., 2004; Starr, 2005; Lin, 2006] and information on spatial structures of soil properties [Chen et al., 1995; van Groenigen, 2000; Thierfelder et al., 2003] and landscape heterogeneity [Manfreda and Rodríguez-Iturbe, 2006] should be exploited.

[10] Figure 1 summarizes measurement techniques addressed in this review. Western and Blöschl [1999] identified a scale triplet that applies both to models and measurements: spacing, extent and support. Spacing refers to the distance between the samples or mode elements, extent refers to the overall coverage and support to the integration volume or area. The black lines in Figure 1 represent the support of each method, whereas the colored areas indicate the potential extent. A major challenge for the future will be the simultaneous use of different measurement technologies and the development of a framework that optimally combines the information contained in the observations with model predictions of soil moisture dynamics at various spatial scales. This will require a concerted action of different research disciplines. The need for such actions becomes more pressing with the establishment of terrestrial observatories that will provide access to multiscale data obtained from a suite of cross-scale measurement methods [e.g., Bogena et al., 2006].

\subsection{Examples of Soil Moisture Measurement Studies}

[11] A large number of experimental field studies provide information about the spatial and temporal variation of soil moisture across a range of spatial scales. Specific attention has been given to (1) the potential of remote sensing to measure near surface soil moisture content and to provide information on probability density functions and statistical moments of soil moisture data [Owe et al., 1982; Famiglietti et al., 1999; Mohanty et al., 2000; Ryu and Famiglietti, 2005; Choi et al., 2007], (2) the identification of spatial organization of soil moisture [Grayson et al., 1997; Western et al., 1999; Western and Blöschl, 1999; Rodriguez-Iturbe et al., 1995; Oldak et al., 2002; Thierfelder et al., 2003]; and (3) investigation of temporal stability of spatial patterns at the field [Kachanoski and de Jong, 1988; Starks et al., 2006] and catchment scale [Grayson and Western, 1998; Mohanty and Skaggs, 2001; Cosh et al., 2004, 2006].

[12] At the field and hillslope scale, various soil moisture data sets are available providing information on (1) the statistical moments of near surface soil moisture content [Brocca et al., 2007]; (2) the spatial organization and time stability of soil moisture patterns [Reid, 1973; Niemann and Edgell, 1993; Kamgar et al., 1993; Famiglietti et al., 1998; Wendroth et al., 1999a; Jacques et al., 2001; De Lannoy et al., 2006; Teuling et al., 2006]; (3) the temporal stability of soil moisture profiles [Vachaud et al., 1985; Comegna and Basile, 1994; Gomez-Plaza et al., 2000; Martinez-Fernandez and Ceballos, 2003; Pachepsky et al., 2005; Lin, 2006]; and (4) the parameters and factors controlling the spatial variability of soil moisture, such as vegetation, soil texture, topography and rainfall [Hawley et al., 1983; Coronato and Bertiller, 1996; Pariente, 2002; Western et al., 2004; Wilson et al., 2005; Buttafuoco and Castrignano, 2005; Lin, 2006; 
Tromp-van Meerveld and McDonnell, 2006; Teuling et al., 2007].

[13] At the catchment scale, large measurement campaigns have focused on validation of remote sensing methods. Ground-based soil moisture measurements from these campaigns were typically restricted to the first few centimeters of the soil profile, and did not provide information about deeper soil layers [Choi and Jacobs, 2007], nor did they infer subsurface properties. Yet, catchment-wide information about moisture dynamics at multiple depths is highly desirable as this contains important information about hydrological fluxes. Unfortunately, there are only very few data sets with measurements of both catchment-wide soil moisture dynamics in the topsoil and measurements of evapotranspiration, groundwater level, moisture content of deeper layers and hydraulic properties [e.g., Western and Grayson, 1998; Mohanty et al., 2002]. The collection of such data sets is one of the challenges that should be addressed in the terrestrial observatories that are currently being established.

[14] At the global scale, Robock et al. [2000] report on the establishment of a soil moisture database. This database presently includes soil moisture observations from more than 600 stations covering a large variety of climates. It supports temporal and spatial analyses of soil moisture, the evaluation of land-surface-atmosphere parameterization schemes, the design of soil moisture observational networks and the validation of remote sensing methods for soil moisture mapping.

\subsection{Vadose Zone Modeling Approaches}

[15] In vadose zone hydrology, there has been a strong tradition in using the Richards equation to describe water movement. In this equation, the mass conservation equation,

$$
\frac{\partial \theta}{\partial t}=-\frac{\partial q_{i}}{\partial x_{i}}-S(h)
$$

is combined with Darcy's law,

$$
q_{i}=-K(h)\left[\frac{\partial\left(h+x_{3}\right)}{\partial x_{i}}\right]
$$

which results in

$$
\frac{\partial \theta}{\partial t}=\frac{\partial}{\partial x_{i}}\left[K(h) \frac{\partial}{\partial x_{i}}\left(h+x_{3}\right)\right]-S(h),
$$

where $\theta$ is the soil moisture content, $q_{i}$ is the water flux, $h$ is the soil matric potential, $K$ is the hydraulic conductivity, $t$ is time, $S$ is a sink term to account for plant root water uptake, and $x_{i}$ are the Cartesian coordinates. The coordinate axis in the vertical dimension is defined by $x_{3}$. To solve equation (3), the moisture retention characteristic, $\theta(h)$, the hydraulic conductivity function, $K(h)$, and the initial and boundary conditions need to be defined. The validity of the Richards equation has been evaluated using controlled experiments at the column scale assuming one-dimensional water flow. Typically, these experiments combine measurements of soil moisture and matric potential. The Richards equation in one or more dimensions has been successfully applied to describe soil water fluxes at the field scale [e.g.,
Vereecken et al., 1991; Clemente et al., 1994; Herbst et al., 2005; Mortensen et al., 2006], the hillslope scale [Nieber and Walter, 1981; Bronstert and Plate, 1997] and the catchment scale [e.g., Herbst and Diekkrüger, 2003; Schoups et al., 2005a]. Two- or even three-dimensional descriptions of water flow processes at larger scales might be warranted when lateral processes such as overland and subsurface flow determine soil moisture dynamics.

[16] Despite these successful applications, the appropriateness of the Richards equation is still under debate. A detailed investigation of its validity is hampered by the inherent spatial variability of soils, the current inability to obtain spatially averaged measurements of matric potential, and the difficulty of accurately measuring boundary conditions at larger spatial scales. While an accurate mathematical formulation of flow and transport is of utmost importance, an appropriate model dimension must be selected that adequately reflects the field situation. For the sake of computational simplicity, soil moisture data are often analyzed using one-dimensional models, which assume that flow occurs only vertically. However, to assess the validity of this assumption a comparison with multidimensional flow models is required [e.g., Vrugt et al., 2001a]. Inappropriate selection of model dimensionality will not only corrupt soil hydraulic parameter estimates, but also reduces the accuracy of model predictions of soil moisture. Examples where consideration of horizontal flow might be important include analysis of the response of an aquifer to groundwater pumping, and analysis of soil profile moisture in humid landscapes were lateral flow is an important contribution to runoff. Unfortunately, these systems are often modeled as one dimensional because of our inability to appropriately populate multidimensional models with hydraulic properties, and absence of reliable information about spatially varying boundary conditions. The extent to which dimensionality affects the optimized values of the soil hydraulic properties and the interpretation of model predicted moisture patterns needs to be investigated in more detail.

[17] The catchment and land surface hydrology community have embraced the use of relatively simple water balance models without a full characterization of the $\theta(h)$ and $K(h)$ functions [e.g., Boulet et al., 2000; Demarty et al., 2005; Decharme and Douville, 2007]. These models are sometimes cast in a stochastic framework to analyze the spatial and temporal variation of soil moisture induced by the spatial and temporal variation of vegetation and rainfall [Entekhabi and Rodriguez-Iturbe, 1994; Laio et al., 2002; Ridolfi et al., 2003; Isham et al., 2005; Rodriguez-Iturbe et al., 2006; Botter et al., 2007; Settin et al., 2007]. In these approaches, soil moisture is typically modeled by simplified moisture balance equations [Rodriguez-Iturbe et al., 1999; Albertson and Montaldo, 2003; Montaldo and Albertson, 2003b] that are similar to the capacity type bucket models often used in conceptual rainfall-runoff models. This is nicely illustrated by the work of Albertson and Montaldo [2003], who presented a theoretical framework to analyze temporal variability of root zone soil moisture. As in the derivation of the Richards equation, they start with the mass balance and Darcy equation. By integrating the mass balance over the root zone, defining the input and output fluxes and by applying a spatial averaging operator over a 
specified horizontal grid cell $\left(\mathrm{x}_{1}, \mathrm{x}_{2}\right)$, they obtain an averaged (coarse-grained) soil moisture equation,

$$
\frac{\partial \bar{\theta}}{\partial t}=\frac{1}{L_{v}}\left(\bar{I}-\overline{q_{r}}-\overline{E_{o}}-\bar{T}\right)-\frac{\partial \bar{q}_{1}}{\partial x_{1}}-\frac{\partial \bar{q}_{2}}{\partial x_{2}}
$$

where $L_{v}$ is the rooting depth, $I$ is the infiltration rate, $E_{o}$ is the bare soil evaporation, $T$ is the transpiration rate and the overbars denote spatially averaged values. A unit gradient in matric potential was assumed to quantify the vertical drainage flux $\left(q_{r}\right)$, which implies knowledge of the hydraulic conductivity function. The lateral flux between adjacent horizontal cells was calculated by

$$
q_{x_{i}}=-K_{s} \theta \frac{\partial z}{\partial x_{i}}, \quad i=1,2
$$

where $z$ is the topographic height. Infiltration is controlled by the saturated moisture content. Actual evapotranspiration was described by a piecewise linear function of soil moisture requiring information on the moisture content for which the transpiration is less than the potential rate and the moisture content for which transpiration ceases. When lateral fluxes are neglected, equation (4) describes the wellknown tipping bucket model for a soil with one layer.

[18] Both potential and water content-based approaches are viable approaches to model water movement. Soil water balance models directly address moisture content as the variable of interest and assume gravity as the driving force for water flow, whereas models using the Richards equation include both matric potential and gravity as the driving forces. There are several reasons for favoring a soil moisture-based approach.

[19] 1. Estimation of effective soil water fluxes using Richards-based approaches heavily relies on knowledge of effective soil hydraulic parameters at the scale of interest and the validity of a capillary-based concept at larger scales. Although upscaling approaches enable estimation of effective properties from local-scale hydraulic properties, their validity is mostly limited to specific flow conditions. Further developments in both upscaling theories and measurement technologies quantifying effective state variables and fluxes are needed to eliminate these limitations. Moreover, the nature of the spatial structure of hydraulic parameters is typically unknown and its determination requires substantial efforts. In contrast, simple mass balance approaches have been postulated that may be considered scale-invariant, robust and parsimonious in terms of parameter specification and estimation.

[20] 2. Soil moisture can be measured at a variety of scales and often in a nondestructive manner with a high temporal and spatial resolution. This is not possible for soil matric potential, which can only be measured at the point scale.

[21] 3. Near surface soil moisture content is important for the partitioning of water and energy fluxes. For example, soil moisture content is a key variable in the estimation of evapotranspiration fluxes from the soil and it is well known to exhibit a nonlinear relationship [Wetzel and Chang, 1987; Crow and Wood, 2002a].

[22] 4. Soil moisture measurements are typically more accurate than matric potential measurements. Additionally, soil moisture measurements cover the whole range, whereas conventional matric potential measurements only cover the wet part of the moisture retention characteristic. Recently, new tensiometers have been developed that significantly extend the range of soil matric potential measurements [e.g., Bakker et al., 2007]. However, these new sensors have not yet found widespread use.

[23] Despite these advantages, closure of the mass balance in the water content-based (bucket-type) models still requires constitutive equations for the unknown mass fluxes, such as internal drainage, lateral flow, capillary rise and evaporation [Reggiani et al., 2000]. These fluxes are usually derived on the basis of flux potential gradient relationships such as Darcy's law (equation (2)). However, this equation requires the specification of the hydraulic conductivity relationship, which is difficult to obtain. Also the prediction of root water uptake requires adequate knowledge of both the hydraulic conductivity and the soil moisture retention functions (see section 6.4). Therefore, the issue of closing the mass balance is often solved by using simplified descriptions that neglect specific processes or by linearization of the constitutive equations. To what extent this limits the validity of the obtained results is not really known or studied. Even when more accurate soil moisture measurements become available, the specification of these constitutive equations will remain a requirement. One potential way out of this dilemma are direct measurements of hydrological fluxes. Unfortunately, there is a lack of methods to measure subsurface hydrological fluxes. At the point scale, heat pulse methods have been used to measure the soil moisture flux directly [e.g., Ren et al., 2000; Mori et al., 2005]. At the hillslope scale, Retter et al. [2006] used slanted TDR probes to estimate soil moisture fluxes. It seems promising to explore the usefulness of these methods at larger scales (e.g., by integration in sensor networks).

\section{Data Assimilation Methods for Estimating Vadose Zone Properties and Fluxes From Measured Soil Moisture Data}

[24] A large number of methods are presently available that enable the assimilation of soil moisture measurements in models to estimate vadose zone properties and predict fluxes. In this section, we will summarize the key methods: direct insertion, statistical correction assimilation, Newtonian nudging, inverse modeling, variational approaches and sequential data assimilation methods, also known as Kalman filtering (KF) techniques. We do not distinguish explicitly between what sources of information can be used to estimate soil moisture. In the present context, we could distinguish between direct (remote sensing and ground measurements) and indirect sources (soil texture, soil depth and topography). Both of these data sources facilitate updating of model predicted soil moisture content when new observations become available. However, direct measurements will likely contain more information about the moisture content at the scale of interest, and allow for a stronger state update and uncertainty reduction.

\subsection{Direct Insertion and Statistical Correction Assimilation}

[25] In the direct insertion method, simulated values are substituted with observed values as they become available 
[e.g., Houser et al., 1998; Walker et al., 2001a; Heathman et al., 2003]. Typically this is done for the state variable values near the soil surface as they are often readily available and easily accessible for remote sensing and in situ measurement equipment. This approach is similar to defining a Dirichlet-type boundary condition with a value equal to the measured state variable (e.g., soil moisture).

[26] In the statistical correction assimilation method, the statistical moments of the modeled state variables are adjusted to match the statistical moments of the observations [e.g., Houser et al., 1998]. Two assumptions are made in this approach. First, the statistics of the observed values are correct and provide a close approximation of reality. Second, the patterns of the predicted state variables are correct but the statistical moments are biased, which can be corrected by matching against the observed statistical moments [Houser et al., 1998].

\subsection{Newtonian Nudging}

[27] Recently, Newtonian nudging (NN) methods have been introduced in hydrology. In NN, an additional correction term, $N(\mathbf{x}, t)$ is added to a dynamical model of the form

$$
\frac{\partial v}{\partial t}=F(v, \mathbf{x}, t)+N(\mathbf{x}, t)\left(v_{o}-v\right)
$$

where $v$ is the model state variable, $v_{o}$ is the observed value of the state variable and $F$ is the forcing term in the dynamical model. This correction of the forcing term is proportional to the difference between the simulated and observed state variable and it forces the simulation in the direction of the observations. This correction or nudging term may contain information on data quality, nudging influence factors and a priori knowledge on the spatiotemporal variability and characteristic scales of the state variables using four-dimensional weighting functions. Details about the specification of the nudging term can be found in work by Paniconi et al. [2003] and Houser et al. [1998]. Most of the hydrological studies using NN are limited to numerical case studies. These studies showed that NN is computationally efficient. However, NN was found to be sensitive to the parameter settings (e.g., the strength of the nudging term, the frequency of data assimilation), which requires further analysis [Hurkmans et al., 2006].

\subsection{Inverse Modeling}

[28] Inverse modeling estimates the unknown parameters governing the processes and fluxes in the system using independent observations of the system under study [e.g., Yeh, 1986; Abbaspour et al., 1997; Vereecken et al., 2007a]. These observations can include state variables, such as soil moisture or matric potential, and fluxes, such as evapotranspiration and river discharge. In the process of inverse modeling, the model parameters are adjusted to minimize the difference between observed and modeled values. This approach is often referred to as calibration in hydrological literature. The models used in this approach can vary from simple 1-D soil moisture balance models or SVAT models with only a limited number of parameters [e.g., Demarty et al., 2004, 2005; Rushton et al., 2006] to more complex soilvegetation-atmosphere models or large-scale hydrological models [Vrugt et al., 2004; Schoups et al., 2005a, 2005b]. The algorithms used to find the "optimal" parameters may range from simple search algorithms that seek iterative improvement of the objective function starting from a single location in the search space [e.g., Ritter et al., 2003] to more advanced global search methods that utilize the strength of a population of individuals to efficiently search the space of potential solutions and avoid getting stuck in a local minimum of the objective function. Global optimization methods that have been used for the estimation of the unsaturated soil hydraulic properties include the annealing-simplex method [Pan and $W u, 1998]$, genetic algorithms [Takeshita, 1999], multilevel grid sampling strategies [Abbaspour et al., 2001; Lambot et al., 2002], ant colony optimization [Abbaspour et al., 2001], and shuffled complex methods [Vrugt and Bouten, 2002; Mertens et al., 2004, 2005, 2006]. Recent extensions include multiobjective search methods [e.g., Vrugt et al., 2003; Vrugt and Dane, 2005; Mertens et al., 2006], and simultaneous multimethod genetically adaptive optimization algorithms [Vrugt and Robinson, 2007; Wöhling et al., 2008].

\subsection{Kalman Filtering Techniques}

[29] Kalman filtering (KF) was developed in the 1960s for optimal control of systems governed by linear equations [Kalman, 1960] and was introduced into earth system sciences to optimally merge information from uncertain measurements and model predictions [Evensen, 1994; Houtekamer and Mitchell, 1998; Bertino et al., 2003; Annan et al., 2005; Ni-Meister et al., 2006]. Here, we summarize the three most important filters that have found use in vadose zone hydrology: standard Kalman filters, extended Kalman filters and ensemble Kalman filters. Note that a recent review on the use of data assimilation in earth systems science is given by Reichle [2008].

[30] $\mathrm{KF}$ is used to describe linear dynamical systems that are discretized in the time domain. At each moment in time, a linear operator is applied to generate a new state of the system accounting for the presence of system noise and information from controls on the system. To predict the state of the system at time $t$, the KF optimally weights the model predicted state at this time with measured values of the state at this time based on a least squares approach. The KF technique can be considered as the most general estimator for systems governed by linear dynamics. Spatial estimation methods such as kriging, spline interpolation and conditional multivariate normal estimation may be viewed as special steady state versions of KF [e.g., McLaughlin, 1978; Or and Hanks, 1992]. Unfortunately, in most real world studies, system dynamics are not linear but governed by nonlinear stochastic difference equations. In these situations, the extended KF can be used, which linearizes the state transition (hence error covariance), and observation model using a tangent linear operator [Reichle et al., 2002a, 2002b; Sabater et al., 2007]. Various studies have demonstrated that this linearization is notoriously unstable if the nonlinearity is strong, and therefore an alternative is needed.

[31] Evensen [1994] proposed the ensemble KF (EnKF), which uses a Monte Carlo method to generate an ensemble of model trajectories from which the time evolution of the probability density of the model states, and related error covariances are estimated. The EnKF avoids many of the problems associated with the extended KF. Moreover, the conceptual simplicity, relative ease of implementation and computational efficiency of the EnKF make the method an 
attractive option for data assimilation in vadose zone hydrology. Further developments of the EnKF were proposed by Dunne and Entekhabi [2005] and Pan and Wood [2006].

\subsection{Variational Approaches}

[32] In the variational approach [e.g., Reichle et al., 2001; Sabater et al., 2007], the simulated values of a state variable, $\mathbf{x}$ are adjusted to the observations available within a specified assimilation window, $\mathbf{z}$, defined on the basis of observation times by minimizing a general cost function $\mathbf{J}(\mathbf{x})$ [Sabater et al., 2007]:

$$
\mathbf{J}(\mathbf{x})=\frac{1}{2}\left(\mathbf{x}-\mathbf{x}^{b}\right) \mathbf{B}^{-1}\left(\mathbf{x}-\mathbf{x}^{b}\right)^{T}+\frac{1}{2}\left[( \mathbf { z } - \mathbf { H } ( \mathbf { x } ) ] \mathbf { R } ^ { - 1 } \left[(\mathbf{z}-\mathbf{H}(\mathbf{x})]^{T} .\right.\right.
$$

The observation vector, $\mathbf{z}$, includes all the observations made within a prespecified assimilation window and therefore differs from the sequential time stepping approach used in the KF techniques. The right hand side of equation (7) consists of two terms: a background term $\mathbf{J}_{\mathrm{b}}(\mathbf{x})$ and an observation term $\mathbf{J}_{\mathrm{o}}(\mathbf{x})$. The background term is a measure for the difference between the state vector and its background value weighted by the background error matrix $\mathbf{B}$. The observation term quantifies the difference between the measured and the predicted value for the defined assimilation windows weighted by the measurement error matrix $\mathbf{R}$. This matrix $\mathbf{R}$ is similar to the error matrix used in the KF but differs in the definition of the time scale. The matrix $\mathbf{H}$ projects the model space into the observation space and is therefore similar to the observation operator used in the Kalman filter, but again differs in the time scale considered. In the variational method, the cost function $\mathbf{J}(\mathbf{x})$ is typically minimized by using the gradient descent method, which requires the adjoint and the tangent linear models [Sabater et al., 2007]. Sabater et al. [2007] distinguish two variational approaches: the simplified 1DVAR approach [Balsamo et al., 2004] and the variational tuning method. The latter method neglects the background term $\mathbf{J}_{\mathrm{b}}(\mathbf{x})$ and assumes that $\mathbf{R}=\mathbf{I}$, the identity matrix.

\subsection{Regression Analysis, Empirical Orthogonal Function Approaches, and Interpolation Schemes}

[33] A few authors proposed the use of linear regression equations to derive the soil moisture profile, the soil moisture deficit or the water content at a specific depth from surface soil moisture content [e.g., Arya et al., 1983; Jackson et al., 1987]. Fernandez-Galvez et al. [2006] used a vertical interpolation technique to estimate soil moisture profiles and values of integrated profile moisture content using continuous measurements at a limited number of depths and occasional measurements at a large number of depths. In addition, they developed a temporal interpolation technique to retrieve complete time series of soil moisture for locations with only a limited number of observations using information from time series observed at other nearby locations. This approach is based on the assumption that changes in water content at one location will be similar to changes at nearby locations because of approximate similar atmospheric forcing. At the catchment scale, an empirical orthogonal function analysis [Perry and Niemann, 2007; Jawson and Niemann, 2007] can be used to estimate soil moisture patterns for unobserved times if detailed soil moisture observations are available for a limited period in the past.

\section{Retrieving the Spatial and Temporal Variability of Soil Moisture}

[34] One of the first studies demonstrating that near surface soil moisture content contains useful information to estimate root zone water storage and soil moisture profiles was presented by Camillo and Schmugge [1983]. Since then, many studies have reported similar findings [Kostov and Jackson, 1993; Georgakakos and Baumer, 1996; Calvet et al., 1998; Calvet and Noilhan, 2000; Wendroth et al., 1999b; Li and Islam, 1999; Crow and Wood, 2003, Das and Mohanty, 2006]. Despite this success, there are several issues that require attention and these are discussed below.

\subsection{Importance of Correct Process Description and Hydraulic Parameterization}

[35] Several studies indicate that a successful retrieval of soil moisture profiles requires mathematical models that include the dominant processes for the specific hydrological conditions [Walker et al., 2001a] and a correct specification of hydraulic parameters [e.g., Heathman et al., 2003]. Walker et al. [2001a] used the KF approach with an approximation of the Richards equation to retrieve the soil moisture profile by assimilating measured near surface soil moisture data. Soil moisture retrieval required knowledge of the representative depth of the surface soil moisture measurement, the best possible estimate of the saturated and residual moisture content and a model description considering the dominant processes. In their study, incorporation of a root water uptake model led to an improved characterization of the soil water balance and thus reduced model bias. The implementation of root water uptake was necessary because soil moisture profiles were generally too wet in the summer period. Unfortunately, no quantitative information on the bias reduction was provided. A qualitative comparison of the measured and retrieved soil moisture profiles indicated that the soil water retention parameters were the most important hydraulic parameters for soil moisture retrieval. However, a systematic analysis of the sensitivity of soil moisture retrieval as function of hydraulic parameters was not performed. In contrast, Montaldo and Albertson [2003a] were able to improve the prediction of soil moisture profiles by updating saturated hydraulic conductivity on the basis of a sensitivity analysis of the assimilation protocol to errors in the specified hydraulic properties [Montaldo et al., 2001]. Using actual field data, they showed that the root-mean-square error (RMSE) of soil moisture content could be reduced by a factor of 3 . Further reduction of the RMSE was hampered because of the presence of uncertainty in model physical parameters and the simplified structure of the model. Again, no systematic sensitivity analysis was performed for the other soil hydraulic parameters, such as the air entry value or pore size distribution index parameter. In addition, the soil moisture retention parameters used in the analysis of Walker et al. [2001a] are not explicitly considered by Montaldo and Albertson [2001]. Das and Mohanty [2006] used a onedimensional soil water flow model in combination with an 
ensemble Kalman filter to assimilate remotely sensed surface soil moisture data in order to retrieve the root zone soil moisture. They found that remotely sensed surface soil moisture could not substantially improve root zone soil moisture estimates when soil hydraulic properties were uncertain. This uncertainty resulted from a lack of a priori knowledge about the true soil profile properties such as layering and textural composition. The above studies strongly suggest that accurate knowledge of soil hydraulic properties is important for improved retrieval of soil moisture profiles from surface soil moisture measurements. However, detailed and systematic investigations of the required accuracy and sensitivity of soil hydraulic properties for soil moisture retrieval are still lacking. A first study in this direction was recently published by Ines and Mohanty [2008]. As a priori information on soil hydraulic properties is often not available, the use of pedotransfer functions to estimate soil hydraulic properties should be explored.

\subsection{Role of Initial Soil Moisture Profile}

[36] A few studies addressed the importance of the initial soil moisture profile for assimilation of surface soil moisture measurements. Poor initialization is caused by the lack of a priori knowledge of the true soil moisture content or soil properties. Walker et al. [2001a] studied the impact of poor initialization by specifying initially wet conditions for a dry soil. Das and Mohanty [2006] used a uniform initial soil moisture profile equal to $50 \%$ of relative saturation. Galantowicz [1999] exchanged the true sandy soil profile by a clay loam profile leading to a poor representation of the initial soil moisture profile. All these studies showed that this incorrect initialization is corrected by assimilating near surface soil moisture measurements. For example, Walker et al. [2002] showed that the RMSE of the open loop simulations (i.e., runs without assimilation) can be reduced by more than $50 \%$.

\subsection{Frequency of Soil Moisture Measurements}

[37] Measurement frequency is a key factor for deriving accurate soil moisture profile estimates from surface soil moisture measurements. The update frequency differs considerably between studies and may range from daily updating [Hoeben and Troch, 2000; Li and Islam, 1999], updating every 2 to 3 days [Walker et al., 2002; Pauwels et al., 2007], up to weekly to 2-weekly updating [Calvet et al., 1998; De Lannoy et al., 2007]. Numerical case studies examining the update frequency show that the required assimilation frequency depends on the errors in the model physics and forcing data [Walker et al., 2002]. De Lannoy et al. [2007] found that the optimal assimilation frequency of surface soil moisture to retrieve soil moisture profiles was about one to two weeks after removal of bias in the model specification and forcing. Calvet et al. [1998] required only a few surface soil moisture measurements to accurately retrieve the root zone moisture content during a 6 month study period in spring and autumn. Accuracy was defined in terms of the RMSE, maximum error and mean bias between retrieved total soil moisture content and the reference simulation. Assimilation of five measurements within a 15 day time window resulted in a RMSE of $13.4 \mathrm{~mm}$ in autumn (4\% of the total soil moisture content) and a RMSE of $26 \mathrm{~mm}$ in spring (6-7\% of the total soil moisture content). A sixfold increase of the number of soil moisture measurements reduced the RMSE by $50 \%$ in both spring and autumn. In general, analysis of literature data shows that the optimal assimilation frequency is not determined by one specific factor. Several factors, such as model correctness (e.g., appropriate dominant processes), correct parameterization, appropriate atmospheric forcing (e.g., directly measured surface energy balance components and precipitation data), the assimilation approach, and data quality all play important roles.

\subsection{Decoupling of Surface and Deeper Soil Layers}

[38] The value of surface soil moisture data to retrieve soil moisture profiles might be limited by the lack of correlation between surface and subsurface soil moisture. This is often explained by physical decoupling of adjacent soil layers and may occur when the surface and subsurface drying rates diverge [Capehart and Carlson, 1997]. The strength and occurrence of this decoupling is primarily controlled by the soil hydraulic properties. In coarse textured soil, decoupling may occur because of the breakdown of capillary connectivity. The presence of soil layers with strongly differing hydraulic properties (e.g., by agricultural practices) also favors decoupling. Fine textured soils are less prone to decoupling because of the smooth changes in moisture content and hydraulic conductivity with increasing dryness.

[39] Several studies reported on the importance of coupled surface and subsurface soil moisture content for retrieving soil moisture profiles from near surface measurements [e.g., Walker et al., 2002; De Lannoy et al., 2007]. For example, Walker et al. [2002] could not retrieve vertical soil moisture profiles because of decoupling. This was explained by a combination of strong surface drying and the specific properties of the soil profile, which consisted of a clay layer overlain by sandy loam.

\subsection{Accuracy of Soil Moisture Data}

[40] The accuracy of soil moisture data affects the accuracy of soil moisture profile retrieval [e.g., Georgakakos and Baumer, 1996; Li and Islam, 1999; Hoeben and Troch, 2000; Pauwels et al., 2007]. Available studies diverge with respect to the measurement accuracy that still provides acceptable predictions. This may partly be explained by differences in modeling approach, the use of calibration, the type and accuracy of forcing terms and the assimilation procedure. Georgakakos and Baumer [1996] used a simplified two-layer model that was calibrated to streamflow data to predict flows (e.g., streamflow at the outlet, evaporation) and soil moisture content. Assimilation of surface soil moisture data, even in the presence of substantial error, resulted in improved estimates of the water content in the deeper soil. They considered error levels ranging from $10 \%$ to more than $50 \%$ of the moisture content of the upper soil layer. In contrast, $\mathrm{Li}$ and Islam [1999] showed that soil moisture data with random errors larger than 5\% did not improve soil moisture profile predictions. A similar analysis by Pauwels et al. [2007] showed that modeled soil moisture could only be improved when the observation error was below $0.05 \mathrm{~m}^{3} \mathrm{~m}^{-3}$. This absolute error corresponds with a relative error ranging from 20 to $50 \%$ on the basis of the range of observed soil moisture content in this study. Hoeben and Troch [2000] concluded that active microwave remote sensing measurements, given the present-day obser- 
vation noise, will not substantially improve soil moisture prediction compared to retrievals obtained with open loop simulations. Clearly, consideration of measurement accuracy of satellite systems is a critical issue that requires further attention, especially in the case of remote sensing techniques. Typically, errors in field-based measurement techniques, such as TDR, GPR and capacitance probes, are well below the critical error levels identified above, which supports their value for retrieval of soil moisture profiles.

\subsection{Using Auxiliary Information to Predict Soil Moisture}

[41] Improved retrieval of soil moisture profiles is often accomplished by including additional information besides measured soil moisture data. This may include state variables (e.g., temperature, leaf area index (LAI)), fluxes and spatial attributes. Pauwels et al. [2007] showed that simulated soil moisture profiles improved when both soil moisture and LAI were updated at least every 2 weeks. This also resulted in improved evapotranspiration predictions compared to baseline simulations. However, no clear picture was obtained when only LAI data were assimilated. Entekhabi et al. [1994] demonstrated the value of combining microwave remote sensing and infrared temperature measurements to retrieve soil moisture and heat profiles. Visser et al. [2006] combined online soil moisture data, water table measurements and meteorological data and obtained improved forecasts of water table depth and physically consistent soil moisture profiles. Wilson et al. [2005] proposed a terrain-based method for predicting the spatial distribution of soil moisture. The method exploits the fact that terrain attributes can be related to an average soil wetness index. This dependency is then used to simulate spatial patterns of soil moisture on the basis of an appropriate weighing of the relationship between wetness conditions and terrain and spatial attributes.

[42] Information contained in the spatial dependence of soil moisture has only rarely been exploited in data assimilation studies [e.g., Grayson et al., 2002]. One of the first papers to include spatial information of soil moisture in a $\mathrm{KF}$ approach to estimate the soil water balance was published by $\mathrm{Or}$ and Hanks [1992]. They showed that spatial estimates obtained from a limited number of soil moisture measurements using a conditional multivariate normal method could be successfully used as "new" measurement information in an additional KF updating step. A similar approach to integrate spatial soil moisture information was presented by Parada and Liang [2004] using the multiscale KF technique proposed by Kumar [1999].

\subsection{Strengths and Limitations of Assimilation Methods}

[43] The appropriate choice of assimilation method plays an important role in the retrieval of soil moisture profiles from surface soil moisture measurements. Direct insertion approaches have a limited potential in this respect [Heathman et al., 2003; Francois et al., 2003; Li and Islam, 1999]. Walker et al. [2001b] used a numerical study to compare the ability of the direct insertion and the extended KF approach to retrieve the true soil moisture and temperature profiles by assimilating near-surface soil moisture and temperature data into a soil moisture and heat transfer model. For soil moisture retrieval, they showed that the KF is superior to direct insertion because it is able to correct the entire soil moisture profile, whereas direct insertion only alters the soil moisture values at each observation depth. Houser et al. [1998] compared direct insertion, statistical correction and Newtonian nudging in their ability to predict root zone soil moisture profiles. The best results were obtained by Newtonian nudging, which produced soil moisture fields without discontinuities and retained the observed spatial patterns while making a larger impact on the root zone soil moisture at the same time.

[44] Assimilation methods also differ in terms of flexibility, performance and computational effort. Sabater et al. [2007] compared two types of KF (extended and ensemble) and two variational schemes (variational tuning and simplified 1DVAR) with respect to their potential in retrieving root zone soil moisture from near-surface soil moisture data. In general, all four methods provided satisfactory results. However, the lower computational costs of 1DVAR make it especially suited for operational root zone moisture estimation using remotely sensed surface soil moisture data. Reichle et al. [2002a] compared the performance of the extended and ensemble KF for soil moisture estimation using different numerical case studies. Both KF approaches were able to account for nonlinearities and were found to be equally accurate at comparable computational costs. However, the ensemble Kalman filter was most promising in terms of flexibility and performance.

\section{Estimating Soil Hydraulic Properties From Soil Moisture Data}

[45] The soil water retention characteristic and the hydraulic conductivity function are important properties to describe soil water fluxes. At the column scale, it has now become common practice to estimate these parameters from flux data (e.g., outflow, evaporation), often combined with measurements of matric potential using an inverse modeling framework [e.g., Kool et al., 1987; van Dam et al., 1992; Eching et al., 1994; Vereecken et al., 1997; Simunek et al., 1998; Nutzmann et al., 1998, Vrugt et al., 2001a]. For a detailed discussion on the various column-scale techniques and on the possibilities and limitations of inverse modeling to derive soil hydraulic parameters from unsaturated flow and transport experiments, the reader is referred to reviews of Simunek and Hopmans [2002] and Finsterle [2005].

\subsection{Estimating Field-Scale Soil Hydraulic Properties}

[46] Compared to the extensive use of inverse methods at the column scale, there are only a limited number of studies that use field-scale soil moisture data to inversely estimate hydraulic properties. In general, these studies indicate that the use of soil moisture measurements alone is not sufficient to provide unique and physically reasonable estimates of hydraulic properties at the field scale. Typically, inversions require additional information to constrain parameter estimation. This information may include directly measured matric potential data [Ross, 1993], soil structural information [Abbaspour et al., 2000], homogeneous soil assumption [Ahuja et al., 1993] and measured values of the hydraulic properties [Sisson and van Genuchten, 1991]. In addition, experimental data have often been collected under welldefined flow conditions, such as gravity dominated flow, and bottom boundary conditions prescribing the matric potential [Katul et al., 1993; Wendroth et al., 1993; Eching 
et al., 1994, Abbaspour et al., 1999, 2000]. Successful studies exploit these well defined flow and boundary conditions during inverse simulation [Dane and Hruska, 1983; Sisson and van Genuchten, 1991; Eching and Hopmans, 1993; Si and Kachanoski, 2000]. Dane and Hruska [1983] determined the van Genuchten parameters using measured soil moisture contents during a gravity drainage experiment. They required a known matric potential at the bottom boundary and a known value of the unsaturated hydraulic conductivity before stable inversion results could be obtained. Si and Kachanoski [2000] used an inverse procedure to estimate the hydraulic parameters from an analytical solution for constant flux infiltration from measurements of moisture storage using TDR. They concluded that matric potential measurements of the initial and steady state are required in addition to water storage measurements to obtain accurate estimates of the soil hydraulic conditions.

[47] The conditions imposed during these studies are probably not very representative for the field, where different flow regimes alternate and interact and boundary conditions are fluctuating and typically not as well defined. This is especially true at larger spatial scales. Only a few field studies estimate soil hydraulic parameters from soil moisture data under naturally occurring or transient flow boundary conditions. Ritter et al. [2003] estimated effective hydraulic properties from measured time series of soil moisture content in three different depths under natural boundary conditions. They demonstrated the feasibility of their approach, but suggested that a different measurement design might have substantially reduced the uncertainty associated with the inversely determined parameters. Given the increase in computational power in combination with powerful novel optimization methods, inverse estimation of field-scale effective hydraulic parameters from transient flow data is becoming feasible.

[48] Recently, Yeh et al. [2005] and Ye et al. [2005] explored an alternative approach to derive effective hydraulic properties at the field scale. They used spatial moment analysis of 3-D moisture distributions under transient flow conditions to derive the 3-D effective unsaturated hydraulic conductivity tensor from a water injection experiment. Application of this approach to data from the Hanford site showed that the effective hydraulic conductivity exhibited a moisture-dependent anisotropy. The principal directions of the spatial moments were found to be depth-dependent, as the plume evolved through the subsurface. The effective hydraulic conductivities derived with this approach compared well with lab-scale measurements of unsaturated hydraulic conductivity. Ward et al. [2006] also used spatial moment analysis to derive the upscaled soil hydraulic conductivity and also found saturation-dependent anisotropy.

\subsection{Estimating Effective Hydraulic Properties at the Catchment Scale}

[49] The availability of remotely sensed soil moisture data has opened an unprecedented opportunity to estimate soil hydraulic parameters at the field to the catchment scale using inverse modeling. Feddes et al. [1993] proposed to use remotely sensed estimates of regional latent and sensible heat fluxes to constrain the parameter space of soil hydraulic parameters. Subsequent studies showed the feasibility of this approach [Gouweleeuw et al., 1996; Kabat et al., 1997]. The analysis of Kabat et al. [1997] considered three different sets of information representing various data sources for area-average hydrological variables: surface moisture content of selected profiles on specific days, cumulative evaporation and infiltration data typically available from remote sensing data, and a combination of both data sources. A strong similarity was found between inversely estimated and measured effective hydraulic parameters. They also found that surface soil moisture measurements did not improve the hydraulic parameter estimates compared to use of evaporation and infiltration fluxes only.

[50] Mattikalli et al. [1998a, 1998b] explored the potential of using surface soil moisture content measurements from microwave remote sensing to identify soil texture and to estimate soil hydraulic parameters at the catchment scale. They showed that temporal changes in brightness temperature and soil moisture content were significantly correlated with the ratio of sand to clay and the saturated hydraulic conductivity derived from a generalized Kozeny-Carman equation [Mattikalli et al., 1998a]. Mattikalli et al. [1998b] extended their analysis to estimate saturated hydraulic conductivity values in deeper soil layers using an inverse approach.

\subsection{Outlook}

[51] In general, it seems that soil moisture measurements contain substantial information on soil water processes making them valuable to estimate soil hydraulic properties in an inverse approach at the field or catchment scale. Whether soil moisture measurements alone are sufficient to estimate hydraulic properties depends on the complexity of the vadose system, the amount of a priori knowledge, the uncertainty associated with the measured boundary conditions, and the number and type of parameters to be estimated [e.g., Ines and Mohanty, 2008]. The additional use of energy fluxes to constrain the estimates of effective hydraulic parameters seems promising. At the field scale, energy fluxes can be obtained by micrometeorological measurement techniques (e.g., eddy covariance) or highresolution measurements of surface temperature (e.g., using infrared cameras). The use of this type of data to estimate field-scale hydraulic properties is largely unexplored.

[52] Another promising source of information are hydrogeophysical measurement methods, such as ground penetrating radar (GPR) and electrical resisitivity tomography (ERT). These techniques are increasingly being used to estimate soil hydraulic properties and their spatial distribution at the field scale. The potential of inverse hydrodynamic modeling of water flow combined with GPR measurements of soil moisture content to estimate soil hydraulic parameters has been demonstrated [e.g., Lambot et al., 2004, 2006a, 2006b; Rucker and Ferré, 2004; Kowalsky et al., 2004]. At the field scale, Binley et al. [2002] combined cross-borehole GPR and ERT and used the spatiotemporal dynamics of water flow during a controlled tracer experiment to estimate the vertical effective hydraulic conductivity using inverse modeling. Kowalsky et al. [2004, 2005] used numerical experiments to demonstrate the potential of GPR and hydrological measurements (e.g., moisture content) to derive soil hydraulic parameter distributions in the vadose zone.

[53] Recently, Vereecken et al. [2007b] suggested that the statistical properties of soil water content variability itself can be used to estimate hydraulic properties. Using results 
from stochastic analysis of soil water flow, they proposed a procedure to inversely estimate the effective Brooks-Corey soil hydraulic parameters and their spatial variability. This interesting and scale-independent approach warrants further study.

\section{Estimating Hydrological Fluxes}

[54] In this section, we discuss the use of soil moisture data to characterize hydrological fluxes, such as runoff, groundwater recharge and root water uptake. The quantification of hydrological fluxes from soil moisture data requires the spatiotemporal characterization of soil moisture as well as a hydrological model able to describe these dynamics. The required complexity of this model is determined by the complexity of the system being studied. Most studies dealing with the determination of soil moisture fluxes have dealt with bare soils or deeper vadose zone processes so far. As most soils and catchments are covered with vegetation, the prediction of hydrological fluxes will need to include the characterization of transpiration fluxes. Therefore, this review pays specific attention to the use of soil moisture data in characterizing root water uptake, as this process is strongly linked with the transpiration flux.

\subsection{Soil Water Fluxes}

[55] High spatial and temporal resolution data of soil moisture obtained from either remote sensing or hydrogeophysical methods may be used to derive information on the magnitude and dynamics of water fluxes in soil profiles. There is a long tradition in using measured surface soil moisture content to estimate bare soil evaporation. In the 1980s, Bernard et al. [1981] and Prevot et al. [1984] analyzed the value of remotely sensed soil moisture for estimating bare soil evaporation. Bernard et al. [1981] showed that by assimilating near surface soil moisture measurements every 3 days in a numerical model, the evaporation could be described very well. Prevot et al. [1984] used remotely sensed soil moisture measurements as the upper boundary condition (i.e., direct insertion) in a model based on the Richards equation and found that modeled and measured soil evaporation compared well. Bernard et al. [1986] used an airborne scatterometer (active microwave) to determine the temporal dynamics of near surface soil moisture of bare soils with a daily resolution for three months. Using this data, they were able to quantify the drainage from the surface to the deeper layers. More recently, Jackson et al. [1998] used ground-based L and S band microwave radiometers to monitor soil moisture content during and following irrigation at the plot scale. These measurements suggested the presence of a sharp dielectric boundary that moved downward with time, suggesting the presence of an infiltration front. This shows that plot-scale microwave measurements potentially can be used to determine near-surface infiltration rates.

[56] Despite these successes in characterizing soil water fluxes, the use of remote sensing has been limited to the upper part of the soil profile. To a large extent, the limitations discussed in the context of estimating subsurface soil moisture content from surface soil moisture measurements are also valid for estimating fluxes (e.g., decoupling). Characterization of soil water fluxes from soil moisture measurements cannot rely solely on remote sensing. A combined approach in which remote sensing is combined with in situ measurements seems promising. The in situ measurements (e.g., hydrogeophysical measurements) could provide information on soil moisture dynamics at various depths and remote sensing could provide the required spatial coverage. We will elaborate more on this in section 6.4 on groundwater recharge.

\subsection{Runoff}

[57] The value of soil moisture to improve the prediction of runoff is still under debate [e.g., Henderson-Sellers, 1996; Scipal et al., 2005; Parajka et al., 2006], although it has been recognized that spatial patterns of soil moisture can have a dominant influence on catchment runoff [e.g., Grayson et al., 1997; Merz and Plate, 1997]. A few studies reported improved prediction of runoff or flood events using land surface hydrological models combined with measurements of near surface soil moisture obtained from remote sensing [Francois et al., 2003; Pauwels et al., 2001, 2002; Crow et al., 2005b; Jacobs et al., 2003] or point-scale measurements [Aubert et al., 2003]. Less positive results were reported by Parajka et al. [2006]. They studied the potential of assimilating soil moisture obtained from active microwave radar at a coarse $50 \mathrm{~km}^{2}$ resolution to improve the prediction of soil moisture dynamics and hydrological fluxes in 320 gauged and ungauged Austrian catchments. A plausible explanation for this lack of improvement by soil moisture assimilation may be that runoff was already predicted adequately because of model calibration on runoff data. Similar results have been found for soil moisture profile retrieval for cases where simulations were already quite good (see section 4.5).

[58] Most likely, these conflicting results are related to the use of different windows or sampling volumes of the soil moisture measurement techniques and the scale at which runoff is predicted. In addition, the lack of improvement might be related to the large uncertainty in soil moisture content retrieval from remote sensing (see section 4) and errors in forcing terms [e.g., Francois et al., 2003]. Localscale measurements often include a large component of small-scale variability and do not provide full coverage of the catchment, which reduces their value at the larger scale. Active microwave remote sensing typically measures soil moisture at a coarse resolution (e.g., $50 \mathrm{~km}$ ), which is often considered of less value to study catchment-scale hydrological processes. Disaggregation approaches, such as proposed by Reichle et al. [2001] or Merlin et al. [2006], might contribute to resolving this issue.

\subsection{Groundwater Recharge}

[59] The use of remotely sensed soil moisture to predict groundwater recharge has mainly focused on calibration of hydrological models through adjustment of model parameters [Scott et al., 2000; Jackson, 2002] or the improvement of predicting soil moisture profiles through data assimilation techniques (see section 4). Entekhabi and Moghaddam [2007] outline the potential of spaceborne radars operating at $\mathrm{GHz}$ and sub-GHz frequencies to allow direct measurements of near surface soil moisture in order to provide data to constrain a physically based model approach within a KF framework. Despite the potential of remote sensing techniques in providing a high spatial and temporal coverage of 
near surface moisture content, these data have not yet been directly used in an operational manner to predict groundwater recharge. The major limitation of remotely sensed soil moisture still is the limited sampling depth. A way forward in the quantification of groundwater recharge from sensing information lies therefore in a combination of ground-based measurement techniques that provide the required vertical resolution of the moisture profile combined with the spatial coverage provided by airborne and spaceborne platforms. Hydrogeophysical measurement techniques seem especially promising for improved subsurface characterization. In this respect, there is a need to develop novel data assimilation techniques that are able to integrate both hydrogeophysical and remotely sensed data, as well as spatially distributed soil moisture data. Application of hydrogeophysical methods to characterize spatial and vertical variation of soil moisture will require the development of cheap sensor systems in order to obtain the necessary spatial coverage.

\subsection{Root Water Uptake}

[60] Plant transpiration is an important water flux and has a major impact on other water fluxes (e.g., recharge) and moisture content in the soil. In addition, Vogeler et al. [2001] demonstrated that the vertical distribution of water uptake by plants has an important impact on solute transport. It is known that the spatial arrangement of plants affects the spatiotemporal pattern of soil moisture content and water fluxes in orchards and plantations [Green and Clothier, 1998; Andreu et al., 1997] and in row crops [Li et al., 2002; Hupet and Vanclooster, 2005; Coelho and Or, 1998].

[61] In general, root water uptake models try to predict where water is taken up by plants and under what conditions this uptake is reduced by soil water shortage or soil salinity. Although soil moisture is directly affected by root water uptake, it must not be considered as a driving factor. Water flow toward and within the root system is driven by water potential gradients and is therefore determined by the resistances in the soil-root system. This resistance to flow depends on the resistance of the different water flow paths in the soil-plant continuum, which include flow in the soil, flow across the soil-root interface and flow within the root. The root length density determines the length scale of the flow path in the soil. Often, flow in the soil is the most resistive part. The moisture content changes in time and space may be used to estimate the root water uptake and the root length density using inverse modeling. Musters and Bouten [1999] and Hupet et al. [2002] derived root water uptake parameters (root depth and root density) using a 1-D flow model and found that the root water uptake parameters vary considerably in space. Two and three-dimensional soil moisture patterns were considered by Vrugt et al. [2001b, 2001c] in the calibration of a multidimensional root water uptake model. However, the success of this approach has varied because moisture content also changes because of other soil water fluxes. Hupet et al. [2003] remarked that root water uptake parameters are difficult to estimate when hydraulic soil parameters are uncertain. Musters et al. [2000] and Musters and Bouten [2000] found as well that root water uptake was difficult to estimate on the basis of soil water dynamics alone. Additional measurements of root density, sap flow, soil water potential, and actual plant transpiration help to confine root uptake parameters during inverse modeling.

\section{Estimating Energy Fluxes}

[62] Knowledge of surface soil moisture and its spatial distribution is of utmost importance to understand and predict the partitioning of surface energy fluxes [e.g., Schmugge, 1998; Margulis et al., 2002; Crow and Wood, 2002a]. Neglecting small-scale variability of soil moisture may affect the quality of predicted surface energy fluxes in climate and weather models at the regional scale. According to Crow and Wood [2002a], this can be explained by the highly nonlinear relationship between soil moisture content and evapotranspiration and the highly heterogeneous spatial structure of soil moisture fields. Nonlinear relationships between land surface variables and surface fluxes dictate that grid-scale fluxes in regional models will be sensitive to the absence or presence of subgrid variability of soil moisture [Crow and Wood, 2002a]. Statistical downscaling procedures have been developed that estimate the statistical moments of the soil moisture distribution at the subgrid scale of regional models from coarse resolution soil moisture imagery. Even with the new generation of remotely sensed soil moisture data from the SMOS satellite $(30 \mathrm{~km}$ resolution), disaggregation will remain necessary. One of the most common approaches for disaggregating soil moisture is based on a power law relationship between the variance of the soil moisture distribution and scale [e.g., Crow and Wood, 2002b]. Accounting for this subgrid soil moisture variability, Crow and Wood [2002b] showed that the error of modeled energy surfaces fluxes could be halved for footprints larger than $16 \mathrm{~km}^{2}$. Crow and Wood [2002a] considered three spatial scales for soil moisture (point, field and region) and developed a conceptual link between the impact of soil moisture aggregation on the surface energy surfaces fluxes and the spatial scaling properties of soil moisture fields. As spatial aggregation mainly deals with horizontal and near surface variability of soil moisture, a description of the change of soil moisture content with depth, especially in the topsoil layer, is important in predicting surface energy fluxes correctly. Recent evidence obtained from analyzing multiscale soil moisture data observed at scales ranging between 2.5 and $50 \mathrm{~km}$ showed that the relationship between variance and scale has different slopes. This questions the validity of the scaling concept using a single unique slope [Famiglietti et al., 2008].

[63] Another approach for disaggregation is based on the use of surrogate information that can be mapped with a high spatial resolution and that correlates with soil moisture. This information may include micrometeorological data, soil texture, and land cover data [Reichle et al., 2001]. Merlin et al. [2006] developed an algorithm to disaggregate synthetic near-surface soil moisture SMOS-type data $(50 \mathrm{~km}$ resolution) to the scale of a distributed SVAT model with a resolution of $1 \mathrm{~km}$. The disaggregation procedure used thermal and optical data to disaggregate microwave soil moisture on the basis of a relationship between the soil skin temperature and surface soil moisture. The assimilation of downscaled measurements improved the prediction of the spatial distribution of surface soil moisture and performed better than the open-loop system or the case were coarse- 
scale measurements were assimilated. Errors in surface soil moisture could be reduced from $1.4 \%$ for the open loop simulation to values ranging between -0.11 and $0.25 \%$ depending on the assimilation frequency. In addition, the prediction of latent heat flux was improved both at the fine and coarse scales. Limitations of this synthetic study are that the error sources were known and the coupling between surface temperature and surface soil moisture was relatively strong, which limits the disaggregation scheme to specific climate regions.

[64] Not all studies confirm the importance of subgrid soil moisture variability for predicting large-scale surface fluxes. Sellers et al. [1995] showed that averaged soil moisture fields can be used in large-scale models to predict surface energy fluxes without considering subgrid variability. This was explained by a loss of spatial variation during soil drying, which suppresses the increase in nonlinearity between soil moisture and evapotranspiration. This finding is also supported by Kustas and Jackson [1999] on the basis of data obtained in the little Watchita '92 experiment. Seemingly, the importance of subgrid soil moisture variability for large-scale prediction of surface energy fluxes is still under debate.

[65] Future research should focus on improved upscaling and downscaling techniques [Crow and Wood, 2002a] and the use of innovative measurement techniques. Upscaling strategies based on simple averaging concepts [e.g., Crow et al., 2005a] or stochastic theories developed to upscale soil water processes from the local to the field scale in vadose zone hydrology [Vereecken et al., 2007a, 2007b] may provide scale-appropriate moisture content data or effective properties that can be used in land surface models to predict surface energy fluxes. In addition, the establishment of multiscale sensor networks covering spatial scales up to the relevant footprint sizes of remote sensing platforms for soil moisture, such as SMOS, may contribute in revealing the role of soil moisture variability in predicting surface energy fluxes and provide new information to develop upscaling or downscaling approaches. Results of Famiglietti et al. [2008] indicate that there is an information gap in the very wet and dry range concerning small-scale soil moisture variability (up to $100 \mathrm{~m}$ ), which needs to be overcome to allow further development and validation of upscaling approaches.

\section{Inferring Structural, Textural, and Soil Morphology Parameters}

[66] Soil moisture can be used as a proxy variable to derive information about the structural, textural and morphological properties of the subsurface. Wilson et al. [2003] used information about the spatial and temporal distribution of soil moisture derived from electromagnetic induction measurements to obtain information on subsurface morphology structures related to fast horizontal subsurface water flow. The structure consisted of abrupt textural changes from loess-alluvium to an underlying tertiary sand layer and was expected to greatly influence vertical and horizontal water movement. Dissimilar patterns in electrical bulk conductivity observed during drying of the field site were inferred to be caused by soil moisture variation eventually causing difference in water flow.
[67] Hollenbeck et al. [1996] used passive microwave remote sensing to map areas of relative fast and slow soil surface drying within the HAPEX-Sahel 1992 experiment. These differences in drydown were attributed to heterogeneity in soil hydraulic properties. The observed heterogeneity was then related to available information on soil properties (e.g., textural properties), soil patterns and geomorphologic features (e.g., plateaus and terraces). Chang et al. [2003] used remotely sensed brightness temperature over the Southern Great Plains to derive soil textural information. Chang and Islam [2000] proposed a methodology based on a neural network approach to relate observed brightness temperature and soil moisture to soil textural properties. This methodology follows the approach of Hollenbeck et al. [1996]. The use of brightness temperature data from multiple drying cycles was required to classify the soil texture into more than three categories.

\section{Research Needs and Outlook}

[68] The improved capability to measure soil moisture variation in space and time alone using multiscale and multitemporal soil moisture campaigns is insufficient to improve the characterization and quantification of soil hydraulic parameters and hydrological fluxes. It also requires a correct description of vadose zone processes so that the high-resolution soil moisture measurement can be optimally used. Thus, both improved measurement and modeling methods must be combined to advance the science of vadose zone and catchment hydrology. Moreover, to further improve the hydrologic information content from soil moisture profiles additional data on soils, vegetation and land management practice are required.

[69] Combining hydrogeophysical with remote sensing technologies provides a unique way to quantify the deeper subsurface soil moisture dynamics. We are not aware of any study that integrates both techniques to provide spatial coverage of soil moisture in both horizontal and vertical dimensions with a high temporal resolution. Novel methodologies need to be developed that better capitalize on the information that can be collected with these new measurement techniques. For example, the success of retrieving soil moisture profiles from soil moisture data essentially relies on the type of assimilation method. Recent developments combining Kalman Filters with Markov Chain Monte Carlo methods to simultaneously estimate state variable and system parameters seem promising.

[70] For estimation of soil hydraulic properties, soil moisture data only is often insufficient and additional soil data, such as matric potential, is commonly required. Inclusion of hydrologic and energy fluxes using remote sensing may improve the well posedness of the inverse problem when optimizing for soil hydraulic parameters. Therefore, the application of micrometeorological and ground-based remote sensing techniques creates a unique opportunity to measure field-scale effective fluxes, when used in data assimilation or inverse approaches to estimate field-scale hydraulic parameters.

[71] The validity of downscaling and upscaling concepts of soil moisture and the role of soil moisture variability in determining land surface exchange processes require further attention. There is a pressing need to develop improved 
disaggregation schemes that can better integrate large-scale soil moisture measurements into finer-scale hydrological or SVAT models, thereby increasing the value of remotely sensed soil moisture data. Upscaling methods of local-scale soil moisture for predicting surface energy fluxes and water fluxes also require much more attention. Upscaling theories developed for water flow processes in unsaturated soils may prove useful in this respect, because their potential has not been fully explored. Despite the increasing capabilities of measurement technologies and the development of wireless soil moisture sensing networks, the hydrologic community still lacks a unified concept for multiscale observation and interpretation of soil moisture data. Therefore, multiscale monitoring sites and databases are needed to not only provide local information on spatial and temporal characteristics of near surface soil moisture, surface fluxes and near surface properties, but also to provide detailed information of soil moisture content and water fluxes at the field and catchment scale. This type of data is essential for validating upscaling theories and catchment-scale models. We anticipate that the establishment of long-term terrestrial observatories that aim at multicompartmental and multiscale observation of hydrological processes will help moving these issues forward.

[72] Acknowledgments. The fifth author is supported by a J. Robert Oppenheimer Fellowship from the LANL postdoctoral program.

\section{References}

Abbaspour, K. C., M. T. van Genuchten, R. Schulin, and E. Schlappi (1997), A sequential uncertainty domain inverse procedure for estimating subsurface flow and transport parameters, Water Resour. Res., 33, 18791892, doi:10.1029/97WR01230.

Abbaspour, K. C., M. A. Sonnleitner, and R. Schulin (1999), Uncertainty in estimation of soil hydraulic parameters by inverse modeling: Example lysimeter experiments, Soil Sci. Soc. Am. J., 63, 501-509.

Abbaspour, K., R. Kasteel, and R. Schulin (2000), Inverse parameter estimation in a layered unsaturated field soil, Soil Sci., 165, 109-123, doi:10.1097/00010694-200002000-00002.

Abbaspour, K. C., R. Schulin, and M. T. van Genuchten (2001), Estimating unsaturated soil hydraulic parameters using ant colony optimization, $A d v$. Water Resour., 24, 827-841, doi:10.1016/S0309-1708(01)00018-5.

Ahuja, L. R., O. Wendroth, and D. R. Nielsen (1993), Relationship between initial drainage of surface soil and average profile saturated conductivity, Soil Sci. Soc. Am. J., 57, 19-25.

Akbar, M. A., A. L. Kenimer, S. W. Searcy, and H. A. Torbert (2005), Soil water estimation using electromagnetic induction, Trans. ASAE, 48, $129-135$.

Albertson, J. D., and N. Montaldo (2003), Temporal dynamics of soil moisture variability: 1. Theoretical basis, Water Resour. Res., 39(10), 1274, doi:10.1029/2002WR001616.

Alessi, R. S., and L. Prunty (1986), Soil water determination using fiber optics, Soil Sci. Soc. Am. J., 50, 860-863.

Altese, E., O. Bolognani, M. Mancini, and P. A. Troch (1996), Retrieving soil moisture over bare soil from ERS 1 synthetic aperture radar data: Sensitivity analysis based on a theoretical surface scattering model and field data, Water Resour. Res., 32, 653-661, doi:10.1029/95WR03638.

Andreu, L., J. W. Hopmans, and L. J. Schwankl (1997), Spatial and temporal distribution of soil water balance for a drip-irrigated almond tree, Agric. Water Manage., 35, 123-146, doi:10.1016/S0378-3774(97)00018-8.

Annan, J. D., D. J. Lunt, J. C. Hargreaves, and P. J. Valdes (2005), Parameter estimation in an atmospheric GCM using the ensemble Kalman filter, Nonlinear Processes Geophys., 12, 363-371.

Arya, L. M., J. C. Richter, and J. F. Paris (1983), Estimating profile water storage from surface zone soil-moisture measurements under bare field conditions, Water Resour. Res., 19, 403-412, doi:10.1029/ WR019i002p00403.

Aubert, D., C. Loumagne, L. Oudin, and S. Le Hégarat-Mascle (2003), Assimilation of soil moisture into hydrological models: The sequential method, Can. J. Rem. Sens., 29, 711-717.
Bakker, G., M. J. van der Ploeg, G. H. de Rooij, C. W. Hoogendam, H. P. A. Gooren, C. Huiskes, L. K. Koopal, and H. Kruidhof (2007), New polymer tensiometers: Measuring matric pressures down to the wilting point, Vadose Zone J., 6, 196-202, doi:10.2136/vzj2006.0110.

Balsamo, G., F. Bouyssel, and J. Noilhan (2004), A simplified bidimensional variational analysis of soil moisture from screen-level observations in a mesoscale numerical weather-prediction model, Q. J. R. Meteorol. Soc., 130, 895-915, doi:10.1256/qj.02.215.

Bell, J. P., T. J. Dean, and M. G. Hodnett (1987), Soil-moisture measurement by an improved capacitance technique. 2. Field techniques, evaluation and calibration, J. Hydrol., 93, 79-90, doi:10.1016/ 0022-1694(87)90195-8.

Bernard, R., M. Vauclin, and D. Vidalmadjar (1981), Possible use of active microwave remote-sensing data for prediction of regional evaporation by numerical-simulation of soil-water movement in the unsaturated zone, Water Resour. Res., 17, 1603-1610, doi:10.1029/WR017i006p01603.

Bernard, R., J. V. Soares, and D. Vidalmadjar (1986), Differential bare field drainage properties from airborne microwave observations, Water Resour. Res., 22, 869-875, doi:10.1029/WR022i006p00869.

Bertino, L., G. Evensen, and H. Wackernagel (2003), Sequential data assimilation techniques in oceanography, Int. Stat. Rev., 71, 223-241.

Biftu, G. F., and T. Y. Gan (1999), Retrieving near-surface soil moisture from Radarsat SAR data, Water Resour. Res., 35, 1569-1579, doi:10.1029/1998WR900120.

Binley, A., G. Cassiani, R. Middleton, and P. Winship (2002), Vadose zone flow model parameterisation using cross-borehole radar and resistivity imaging, J. Hydrol., 267, 147-159, doi:10.1016/S0022-1694(02)00146-4.

Blonquist, J. M., Jr., S. B. Jones, and D. A. Robinson (2005a), Standardizing characterization of electromagnetic water content sensors: Part 2. Evaluation of seven sensing systems, Vadose Zone J., 4, 1059-1069, doi: $10.2136 /$ vzj2004.0141.

Blonquist, J. M., Jr., S. B. Jones, and D. A. Robinson (2005b), A time domain transmission sensor with TDR performance characteristics, J. Hydrol., 314, 235-245, doi:10.1016/j.jhydrol.2005.04.005.

Blöschl, G., and M. Sivapalan (1995), Scale issues in hydrological modeling-A review, Hydrol. Processes, 9, 251-290, doi:10.1002/ hyp.3360090305.

Blumberg, D. G., G. Ronen, J. Ben-Asher, V. Freilikher, L. D. Vulfson, and A. L. Kotlyar (2006), Utilizing a P-band scatterometer to assess soil water saturation percent of a bare sandy soil, J. Hydrol., 318, 374378, doi:10.1016/j.jhydrol.2005.06.023.

Bogena, H., K. Schulz, and H. Vereecken (2006), Towards a network of observatories in terrestrial environmental research, Adv. Geosci., 9, 1-6.

Bogena, H. R., J. A. Huisman, C. Oberstdörster, and H. Vereecken (2007), Evaluation of a low-cost soil water content sensor for wireless network applications, J. Hydrol., 344, 32-42, doi:10.1016/j.jhydrol.2007.06.032.

Botter, G., A. Porporato, I. Rodriguez-Iturbe, and A. Rinaldo (2007), Basinscale soil moisture dynamics and the probabilistic characterization of carrier hydrologic flows: Slow, leaching-prone components of the hydrologic response, Water Resour. Res., 43, W02417, doi:10.1029/ 2006WR005043.

Boulet, G., A. Chehbouni, I. Braud, M. Vauclin, R. Haverkamp, and C. Zammit (2000), A simple water and energy balance model designed for regionalization and remote sensing data utilization, Agric. For. Meteorol., 105, 117-132, doi:10.1016/S0168-1923(00)00184-2.

Brocca, L., R. Morbidelli, F. Melone, and T. Moramarco (2007), Soil moisture spatial variability in experimental areas of central Italy, J. Hydrol., 333, 356-373, doi:10.1016/j.jhydrol.2006.09.004.

Bronstert, A., and E. J. Plate (1997), Modelling of runoff generation and soil moisture dynamics for hill slopes and micro-catchments, J. Hydrol., 198, 177-195, doi:10.1016/S0022-1694(96)03306-9.

Buttafuoco, G., and A. Castrignano (2005), Study of the spatio-temporal variation of soil moisture under forest using intrinsic random functions of order k, Geoderma, 128, 208-220, doi:10.1016/j.geoderma.2005.04.004.

Calvet, J.-C., and J. Noilhan (2000), From near-surface to root-zone soil moisture using year-round data, J. Hydrometeorol., 1, 393-411, doi:10.1175/1525-7541(2000)001<0393:FNSTRZ>2.0.CO;2.

Calvet, J. C., J. Noilhan, and P. Bessemoulin (1998), Retrieving the rootzone soil moisture from surface soil moisture or temperature estimates: A feasibility study based on field measurements, J. Appl. Meteorol., 37, 371-386, doi:10.1175/1520-0450(1998)037<0371:RTRZSM>2.0.CO;2.

Camillo, P., and T. J. Schmugge (1983), Estimating soil-moisture storage in the root zone from surface measurements, Soil Sci., 135, 245-264, doi:10.1097/00010694-198304000-00006.

Capehart, W. J., and T. N. Carlson (1997), Decoupling of surface and nearsurface soil water content: A remote sensing perspective, Water Resour. Res., 33, 1383-1395, doi:10.1029/97WR00617. 
Cardell-Oliver, R., M. Kranz, K. Smettem, and K. Mayer (2005), A reactive soil moisture sensor network: Design and field evaluation, Int. J. Distrib. Sensor Networks, 1, 149-162, doi:10.1080/ 15501320590966422

Ceballos, A., K. Scipal, W. Wagner, and J. Martinez-Fernandez (2005), Validation of ERS scatterometer-derived soil moisture data in the central part of the Duero Basin, Spain, Hydrol. Processes, 19, 1549-1566, doi:10.1002/hyp.5585.

Chang, D.-H., and S. Islam (2000), Estimation of soil physical properties using remote sensing and artificial neural network, Remote Sens. Environ., 74, 534-544, doi:10.1016/S0034-4257(00)00144-9.

Chang, D.-H., R. Kothari, and S. Islam (2003), Classification of soil texture using remotely, sensed brightness temperature over the Southern Great Plains, IEEE Trans. Geosci. Remote Sens., 41, 664-674, doi:10.1109/ TGRS.2003.809935.

Chen, J. Y., J. W. Hopmans, and G. E. Fogg (1995), Sampling design for soil-moisture measurements in large field trials, Soil Sci., 159, $155-161$.

Choi, M., and J. M. Jacobs (2007), Soil moisture variability of root zone profiles within SMEX02 remote sensing footprints, Adv. Water Resour., 30, 883-896, doi:10.1016/j.advwatres.2006.07.007.

Choi, M., J. M. Jacobs, and H. H. Cosh (2007), Scaled spatial variability of soil moisture fields, Geophys. Res. Lett., 34, L01401, doi:10.1029/ 2006GL028247.

Clemente, R. S., R. Dejong, H. N. Hayhoe, W. D. Reynolds, and M. Hares (1994), Testing and comparison of three unsaturated soil-water flow models, Agric. Water Manage., 25, 135-152, doi:10.1016/03783774(94)90041-8.

Coelho, E. F., and D. Or (1998), Root distribution and water uptake patterns of corn under surface and subsurface drip irrigation, Plant Soil, 206, 123-136, doi:10.1023/A:1004325219804

Comegna, V., and A. Basile (1994), Temporal stability of spatial patterns of soil-water storage in a cultivated Vesuvian soil, Geoderma, 62, 299-310, doi:10.1016/0016-7061(94)90042-6.

Coronato, F. R., and M. B. Bertiller (1996), Precipitation and landscape related effects on soil moisture in semi-arid rangelands of Patagonia, J. Arid Environ., 34, 1-9, doi:10.1006/jare.1996.0088.

Corwin, D. L., and S. M. Lesch (2005), Characterizing soil spatial variability with apparent soil electrical conductivity I. Survey protocols, Comput. Electron. Agric., 46, 103-133, doi:10.1016/j.compag.2004.11.002.

Cosh, M. H., T. J. Jackson, R. Bindlish, and J. H. Prueger (2004), Watershed scale temporal and spatial stability of soil moisture and its role in validating satellite estimates, Remote Sens. Environ., 92, 427-435, doi:10.1016/ j.rse.2004.02.016.

Cosh, M. H., T. J. Jackson, P. Starks, and G. Heathman (2006), Temporal stability of surface soil moisture in the Little Washita River watershed and its applications in satellite soil moisture product validation, J. Hydrol., 323, 168-177, doi:10.1016/j.jhydrol.2005.08.020.

Crosson, W. L., A. S. Limaye, and C. A. Laymon (2005), Parameter sensitivity of soil moisture retrievals from airborne $\mathrm{C}$ - and $\mathrm{X}$-band radiometer measurements in SMEX02, IEEE Trans. Geosci. Remote Sens., 43, 2842-2853, doi:10.1109/TGRS.2005.857916

Crow, W. T., and E. F. Wood (2002a), Impact of soil moisture aggregation on surface energy flux prediction during SGP'97, Geophys. Res. Lett., 29(1), 1008, doi:10.1029/2001GL013796.

Crow, W. T., and E. F. Wood (2002b), The value of coarse-scale soil moisture observations for regional surface energy balance modeling, J. Hydrometeorol., 3, 467-482, doi:10.1175/1525-7541(2002)003<0467:TVOCSS $>$ 2.0.CO;2.

Crow, W. T., and E. F. Wood (2003), The assimilation of remotely sensed soil brightness temperature imagery into a land surface model using ensemble Kalman filtering: A case study based on ESTAR measurements during SGP97, Adv. Water Resour, 26, 137-149, doi:10.1016/S03091708(02)00088-X.

Crow, W. T., R. Bindlish, and T. J. Jackson (2005a), The added value of spaceborne passive microwave soil moisture retrievals for forecasting rainfall-runoff partitioning, Geophys. Res. Lett., 32, L18401, doi:10.1029/2005GL023543

Crow, W. T., D. Ryu, and J. S. Famiglietti (2005b), Upscaling of field-scale soil moisture measurements using distributed land surface modeling, $A d v$. Water Resour., 28, 1-14, doi:10.1016/j.advwatres.2004.10.004.

Dane, J., and S. Hruska (1983), In-situ determination of soil hydraulic properties during drainage, Soil Sci. Soc. Am. J., 47, 619-624.

Das, N. N., and B. P. Mohanty (2006), Root zone soil moisture assessment using remote sensing and vadose zone modeling, Vadose Zone J., 5, 296-307, doi:10.2136/vzj2005.0033.
Dean, T. J., J. P. Bell, and A. J. B. Baty (1987), Soil-moisture measurement by an improved capacitance technique. 1. Sensor design and performance, J. Hydrol., 93, 67-78, doi:10.1016/0022-1694(87)90194-6.

Decharme, B., and H. Douville (2007), Global validation of the ISBA subgrid hydrology, Clim. Dyn., 29, 21 -37, doi:10.1007/s00382-006-0216-7.

De Lannoy, G. J. M., N. E. C. Verhoest, P. R. Houser, T. J. Gish, and M. Van Meirvenne (2006), Spatial and temporal characteristics of soil moisture in an intensively monitored agricultural field (OPE3), J. Hydrol., 331, 719-730, doi:10.1016/j.jhydrol.2006.06.016.

De Lannoy, G. J. M., P. R. Houser, V. R. N. Pauwels, and N. E. C. Verhoest (2007), State and bias estimation for soil moisture profiles by an ensemble Kalman filter: Effect of assimilation depth and frequency, Water Resour. Res., 43, W06401, doi:10.1029/2006WR005100.

Demarty, J., C. Ottle, I. Braud, A. Olioso, J. P. Frangi, L. A. Bastidas, and H. V. Gupta (2004), Using a multiobjective approach to retrieve information on surface properties used in a SVAT model, J. Hydrol., 287, 214236, doi:10.1016/j.jhydrol.2003.10.003.

Demarty, J., C. Ottle, I. Braud, A. Olioso, J. P. Frangi, H. V. Gupta, and L. A. Bastidas (2005), Constraining a physically based Soil-VegetationAtmosphere Transfer model with surface water content and thermal infrared brightness temperature measurements using a multiobjective approach, Water Resour. Res., 41, W01011, doi:10.1029/2004WR003695.

Drusch, M., E. F. Wood, H. Gao, and A. Thiele (2004), Soil moisture retrieval during the Southern Great Plains Hydrology Experiment 1999: A comparison between experimental remote sensing data and operational products, Water Resour. Res., 40, W02504, doi:10.1029/ 2003WR002441.

Dunne, S., and D. Entekhabi (2005), An ensemble-based reanalysis approach to land data assimilation, Water Resour. Res., 41, W02013, doi:10.1029/2004WR003449.

Eching, S. O., and J. W. Hopmans (1993), Optimization of hydraulic functions from transient outflow and soil-water pressure data, Soil Sci. Soc. Am. J., 57, 1167-1175.

Eching, S. O., J. W. Hopmans, and W. W. Wallender (1994), Estimation of in-situ unsaturated soil hydraulic functions from scaled cumulative drainage data, Water Resour. Res., 30, 2387-2394, doi:10.1029/ 94WR00756.

Entekhabi, D., and M. Moghaddam (2007), Mapping recharge from space: Roadmap to meeting the grand challenge, Hydrogeol. J., 15, 105-116, doi:10.1007/s10040-006-0120-6.

Entekhabi, D., and I. Rodriguez-Iturbe (1994), Analytical framework for the characterization of the space-time variability of soil moisture, $A d v$. Water Resour., 17, 35-45, doi:10.1016/0309-1708(94)90022-1.

Entekhabi, D., H. Nakamura, and E. G. Njoku (1994), Solving the inverse problems for soil-moisture and temperature profiles by sequential assimilation of multifrequency remotely-sensed observations, IEEE Trans. Geosci. Remote Sens., 32, 438-448, doi:10.1109/36.295058.

Eppstein, M. J., and D. E. Dougherty (1998), Efficient three-dimensional data inversion: Soil characterization and moisture monitoring from crosswell ground-penetrating radar at a Vermont test site, Water Resour. Res., 34, 1889-1900, doi:10.1029/98WR00776.

Evensen, G. (1994), Sequential data assimilation with a nonlinear quasigeostrophic model using Monte Carlo methods to forecast error statistics, J. Geophys. Res., 99, 10,143-10,162, doi:10.1029/94JC00572.

Evett, S. R., and G. W. Parkin (2005), Advances in soil water content sensing: The continuing maturation of technology and theory, Vadose Zone J., 4, 986-991, doi:10.2136/vzj2005.0099.

Famiglietti, J. S., J. W. Rudnicki, and M. Rodell (1998), Variability in surface moisture content along a hillslope transect: Rattlesnake Hill, Texas, J. Hydrol., 210, 259-281, doi:10.1016/S0022-1694(98)00187-5.

Famiglietti, J. S., J. A. Devereaux, C. A. Laymon, T. Tsegaye, P. R. Houser, T. J. Jackson, S. T. Graham, M. Rodell, and P. J. van Oevelen (1999), Ground-based investigation of soil moisture variability within remote sensing footprints during the Southern Great Plains 1997 (SGP97) Hydrology Experiment, Water Resour. Res., 35, 1839-1851, doi:10.1029/1999WR900047.

Famiglietti, J. S., D. Ryu, A. A. Berg, M. Rodell, and T. J. Jackson (2008), Field observations of soil moisture variability across scales, Water Resour. Res., 44, W01423, doi:10.1029/2006WR005804.

Fares, A., and V. O. Polyakov (2006), Advances in crop water management using capacitive water sensors, in Advances in Agronomy, edited by D. Sparks, pp. 43-77, Academic, Amsterdam.

Feddes, R. A., M. Menenti, P. Kabat, and W. G. M. Bastiaanssen (1993), Is large-scale inverse modeling of unsaturated flow with areal average evaporation and surface soil-moisture as estimated from remote-sensing feasible, J. Hydrol., 143, 125-152, doi:10.1016/0022-1694(93)90092-N. 
Fernandez-Galvez, J., L. P. Simmonds, and E. Barahona (2006), Estimating detailed soil water profile records from point measurements, Eur. J. Soil Sci., 57, 708-718.

Fields, A., R. Swain, R. Kennedy, W. Belisle, T. Coleman, and A. Sharma (2000), Laboratory and field measurements with a fiber-optic soil moisture sensor, Proc. SPIE, 4087, 1180-1187, doi:10.1117/12.406365.

Finsterle, S. (2005), Multiphase inverse modeling: Review and iTOUGH2 applications, Vadose Zone J., 3, 747-762.

Francois, C., A. Quesney, and C. Ottle (2003), Sequential assimilation of ERS-1 SAR data into a coupled land surface-hydrological model using an extended Kalman filter, J. Hydrometeorol., 4, 473-487, doi:10.1175/ 1525-7541(2003)4<473:SAOESD>2.0.CO;2.

Galantowicz, J. F. (1999), Tests of sequential data assimilation for retrieving profile soil moisture and temperature from observed L-band radiobrightness, IEEE Trans. Geosci. Remote Sens., 37, 1860-1870, doi:10.1109/36.774699.

Garrido, F., M. Ghodrati, and M. Chendorain (1999), Small-scale measurement of soil water content using a fiber optic sensor, Soil Sci. Soc. Am. J., 63, $1505-1512$.

Georgakakos, K., and O. W. Baumer (1996), Measurement and utilization of on-site soil moisture data, J. Hydrol., 184, 131-152, doi:10.1016/ 0022-1694(95)02971-0.

Gillies, R. R., and T. N. Carlson (1995), Thermal remote-sensing of surface soil-water content with partial vegetation cover for incorporation into climate models, J. Appl. Meteorol., 34, 745-756, doi:10.1175/15200450(1995)034<0745:TRSOSS $>2.0 . \mathrm{CO} ; 2$.

Gomez-Plaza, A., J. Alvarez-Rogel, J. Albaladejo, and V. M. Castillo (2000), Spatial patterns and temporal stability of soil moisture across a range of scales in a semi-arid environment, Hydrol. Processes, 14, 1261 - 1277, doi:10.1002/(SICI)1099-1085(200005)14:7<1261::AIDHYP40>3.0.CO;2-D.

Gouweleeuw, B. T., A. A. van de Griend, and M. Owe (1996), Estimation of "effective" soil hydraulic properties by top soil moisture and evaporation modeling applied to an arable site in central Spain, Water Resour. Res., 32, 1387-1392, doi:10.1029/96WR00197.

Goyal, V. C., P. K. Gupta, S. M. Seth, and V. N. Singh (1996), Estimation of temporal changes in soil moisture using resistivity method, Hydrol. Processes, 10, 1147-1154, doi:10.1002/(SICI)1099-1085(199609)10:9< 1147::AID-HYP366>3.0.CO;2-S.

Grayson, R. B., and A. W. Western (1998), Towards areal estimation of soil water content from point measurements: Time and space stability of mean response, J. Hydrol., 207, 68-82, doi:10.1016/S00221694(98)00096-1.

Grayson, R. B., A. W. Western, F. H. S. Chiew, and G. Blöschl (1997), Preferred states in spatial soil moisture patterns: Local and nonlocal controls, Water Resour. Res., 33, 2897-2908, doi:10.1029/ 97WR02174.

Grayson, R. B., G. Blöschl, A. W. Western, and T. A. McMahon (2002), Advances in the use of observed spatial patterns of catchment hydrological response, Adv. Water Resour., 25, 1313-1334, doi:10.1016/S03091708(02)00060-X.

Green, S., and B. Clothier (1998), The root zone dynamics of water uptake by a mature apple tree, Plant Soil, 206, 61-77, doi:10.1023/ A:1004368906698.

Hawley, M. E., T. J. Jackson, and R. H. McCuen (1983), Surface soilmoisture variation on small agricultural watersheds, J. Hydrol., 62, 179-200, doi:10.1016/0022-1694(83)90102-6.

Heathman, G. C., P. J. Starks, L. R. Ahuja, and T. J. Jackson (2003), Assimilation of surface soil moisture to estimate profile soil water content, J. Hydrol., 279, 1-17, doi:10.1016/S0022-1694(03)00088-X.

Henderson-Sellers, A. (1996), Soil moisture simulation: Achievements of the RICE and PILPS intercomparison workshop and future directions, Global Planet. Change, 13, 99-115, doi:10.1016/0921-8181(95) 00035-6.

Herbst, M., and B. Diekkrüger (2003), Modelling the spatial variability of soil moisture in a micro-scale catchment and comparison with field data using geostatistics, Phys. Chem. Earth, 28, 239-245.

Herbst, M., W. Fialkiewicz, T. Chen, T. Putz, D. Thiery, C. Mouvet, G. Vachaud, and H. Vereecken (2005), Intercomparison of flow and transport models applied to vertical drainage in cropped lysimeters, Vadose Zone J., 4, 240-254, doi:10.2136/vzj2004.0070.

Hoeben, R., and P. A. Troch (2000), Assimilation of active microwave observation data for soil moisture profile estimation, Water Resour. Res., 36, 2805-2819, doi:10.1029/2000WR900100.

Hollenbeck, K. J., T. J. Schmugge, G. M. Hornberger, and J. R. Wang (1996), Identifying soil hydraulic heterogeneity by detection of relative change in passive microwave remote sensing observations, Water Resour. Res., 32, 139-148, doi:10.1029/95WR02916.

Houser, P. R., W. J. Shuttleworth, J. S. Famiglietti, H. V. Gupta, K. H. Syed, and D. C. Goodrich (1998), Integration of soil moisture remote sensing and hydrologic modeling using data assimilation, Water Resour. Res., 34, 3405-3420, doi:10.1029/1998WR900001.

Houtekamer, P. L., and H. L. Mitchell (1998), Data assimilation using an ensemble Kalman filter technique, Mon. Weather Rev., 126, 796-811, doi:10.1175/1520-0493(1998)126<0796:DAUAEK>2.0.CO;2.

Huisman, J. A., C. Sperl, W. Bouten, and J. M. Verstraten (2001), Soil water content measurements at different scales: Accuracy of time domain reflectometry and ground-penetrating radar, J. Hydrol., 245, 48-58, doi:10.1016/S0022-1694(01)00336-5.

Huisman, J. A., J. Snepvangers, W. Bouten, and G. B. M. Heuvelink (2002), Mapping spatial variation in surface soil water content: Comparison of ground-penetrating radar and time domain reflectometry, J. Hydrol., 269, 194-207, doi:10.1016/S0022-1694(02)00239-1.

Huisman, J. A., S. S. Hubbard, J. D. Redman, and A. P. Annan (2003), Measuring soil water content with ground penetrating radar: A review, Vadose Zone J., 2, 476-491.

Hupet, F., and A. Vanclooster (2005), Micro-variability of hydrological processes at the maize row scale: Implications for soil water content measurements and evapotranspiration estimates, J. Hydrol., 303, 247270, doi:10.1016/j.jhydrol.2004.07.017.

Hupet, F., S. Lambot, M. Javaux, and M. Vanclooster (2002), On the identification of macroscopic root water uptake parameters from soil water content observations, Water Resour. Res., 38(12), 1300, doi:10.1029/2002WR001556.

Hupet, F., S. Lambot, R. A. Feddes, J. C. van Dam, and M. Vanclooster (2003), Estimation of root water uptake parameters by inverse modeling with soil water content data, Water Resour. Res., 39(11), 1312, doi:10.1029/2003WR002046.

Hurkmans, R., C. Paniconi, and P. A. Troch (2006), Numerical assessment of a dynamical relaxation data assimilation scheme for a catchment hydrological model, Hydrol. Processes, 20, 549-563, doi:10.1002/ hyp.5921.

Hymer, D. C., M. S. Moran, and T. O. Keefer (2000), Soil water evaluation using a hydrologic model and calibrated sensor network, Soil Sci. Soc. Am. J., 64, 319-326.

Hyndman, D. W., and S. M. Gorelick (1996), Estimating lithologic and transport properties in three dimensions using seismic and tracer data: The Kesterson aquifer, Water Resour. Res., 32, 2659-2670, doi:10.1029/ 96WR01269.

Ines, A. M. V., and B. P. Mohanty (2008), Near-surface soil moisture assimilation for quantifying effective soil hydraulic properties under different hydrocolimatic conditions, Vadose Zone J., 7, 39-52, doi:10.2136/vzj2007.0048.

Isham, V., D. R. Cox, I. Rodriguez-Iturbe, A. Porporato, and S. Manfreda (2005), Representation of space-time variability of soil moisture, Proc. $R$. Soc., Ser. A, 461, 4035-4055, doi:10.1098/rspa.2005.1568.

Jackson, T. J. (1993), Measuring surface soil-moisture using passive microwave remote-sensing, Hydrol. Processes, 7, 139-152, doi:10.1002/ hyp. 3360070205 .

Jackson, T. J. (2002), Remote sensing of soil moisture: Implications for groundwater recharge, Hydrogeol. J., 10, 40-51, doi:10.1007/s10040001-0168-2.

Jackson, T. J., M. E. Hawley, and P. E. Oneill (1987), Preplanting soil-moisture using passive microwave sensors, Water Resour. Bull., 23, 11-19.

Jackson, T. J., et al. (1992), Multifrequency passive microwave observations of soil moisture in an arid rangeland environment, Int. J. Remote Sens., 13, 573-580, doi:10.1080/01431169208904059.

Jackson, T. J., D. M. Levine, A. J. Griffis, D. C. Goodrich, T. J. Schmugge, C. T. Swift, and P. E. Oneill (1993), Soil moisture and rainfall estimation over a semiarid environment with the ESTAR microwave radiometer, IEEE Trans. Geosci. Remote Sens., 31, 836-841, doi:10.1109/ 36.239906.

Jackson, T. J., D. M. Levine, C. T. Swift, T. J. Schmugge, and F. R. Schiebe (1995), Large-area mapping of soil moisture using the ESTAR passive microwave radiometer in Washita92, Remote Sens. Environ., 54, 27-37, doi:10.1016/0034-4257(95)00084-E.

Jackson, T. J., T. J. Schmugge, P. E. O’Neill, and M. B. Parlange (1998), Soil water infiltration observation with microwave radiometers, IEEE Trans. Geosci. Remote Sens., 36, 1376-1383, doi:10.1109/36.718838.

Jackson, T. J., D. M. Le Vine, A. Y. Hsu, A. Oldak, P. J. Starks, C. T. Swift, J. D. Isham, and M. Haken (1999), Soil moisture mapping at regional scales using microwave radiometry: The Southern Great Plains Hydrology 
Experiment, IEEE Trans. Geosci. Remote Sens., 37, 2136-2151, doi:10.1109/36.789610.

Jacobs, J. M., D. A. Myers, and B. M. Whitfield (2003), Improved rainfall/ runoff estimates using remotely sensed soil moisture, J. Am. Water Resour. Assoc., 39, 313-324, doi:10.1111/j.1752-1688.2003.tb04386.x.

Jacobs, J. M., B. P. Mohanty, E. C. Hsu, and D. Miller (2004), SMEX02: Field scale variability, time stability and similarity of soil moisture, Remote Sens. Environ., 92, 436-446, doi:10.1016/j.rse.2004.02.017.

Jacques, D., B. Mohanty, A. Timmerman, and J. Feyen (2001), Study of time dependency of factors affecting the spatial distribution of soil water content in a field-plot, Phys. Chem. Earth, Part B, 26, 629-634, doi:10.1016/S1464-1909(01)00060-0.

Jawson, S. D., and J. D. Niemann (2007), Spatial patterns from EOF analysis of soil moisture at a large scale and their dependence on soil, land-use, and topographic properties, Adv. Water Resour., 30, 366-381, doi:10.1016/j.advwatres.2006.05.006.

Kabat, P., R. W. A. Hutjes, and R. A. Feddes (1997), The scaling characteristics of soil parameters: From plot scale heterogeneity to subgrid parameterization, J. Hydrol., 190, 363-396, doi:10.1016/S00221694(96)03134-4.

Kachanoski, R. G., and E. de Jong (1988), Scale dependence and the temporal persistence of spatial patterns of soil water storage, Water Resour. Res., 24, 85-91.

Kalman, R. E. (1960), A new approach to linear filtering and prediction problems, Trans. ASME, Ser. D, 82, 33-45.

Kamgar, A., J. W. Hopmans, W. W. Wallender, and O. Wendroth (1993), Plotsize and sample number for neutron probe measurements in smallfield trials, Soil Sci., 156, 213-224, doi:10.1097/00010694-19931000000001.

Katra, I., D. G. Blumberg, H. Lavee, and P. Sarah (2006), A method for estimating the spatial distribution of soil moisture of arid microenvironments by close range thermal infrared imaging, Int. J. Remote Sens., 27, 2599-2611, doi:10.1080/01431160500522684.

Katra, I., D. G. Blumberg, H. Lavee, and P. Sarah (2007), Topsoil moisture patterns on arid hillsides-Micro-scale mapping by thermal infrared images, J. Hydrol., 334, 359-367, doi:10.1016/j.jhydrol.2006.10.023.

Katul, G. G., O. Wendroth, M. B. Parlange, C. E. Puente, M. V. Folegatti, and D. R. Nielsen (1993), Estimation of in situ hydraulic conductivity function from nonlinear filtering theory, Water Resour. Res., 29, $1063-$ 1070, doi:10.1029/92WR02593.

Kerr, Y. H. (2007), Soil moisture from space: Where are we?, Hydrogeol. J., 15, 117-120, doi:10.1007/s10040-006-0095-3.

Kerr, Y. H., P. Waldteufel, J. P. Wigneron, J. M. Martinuzzi, J. Font, and M. Berger (2001), Soil moisture retrieval from space: The Soil Moisture and Ocean Salinity (SMOS) mission, IEEE Trans. Geosci. Remote Sens., 39, 1729-1735, doi:10.1109/36.942551.

Kool, J. B., J. C. Parker, and M. T. van Genuchten (1987), Parameter estimation for unsaturated flow and transport models-A review, J. Hydrol., 91, 255-293, doi:10.1016/0022-1694(87)90207-1.

Kostov, K. G., and T. J. Jackson (1993), Estimating profile soil moisture from surface layer measurements-A review, Proc. SPIE, 1941, 125-136.

Kowalsky, M. B., S. Finsterle, and Y. Rubin (2004), Estimating flow parameter distributions using ground-penetrating radar and hydrological measurements during transient flow in the vadose zone, Adv. Water Resour., 27, 583-599, doi:10.1016/j.advwatres.2004.03.003.

Kowalsky, M. B., S. Finsterle, J. Peterson, S. Hubbard, Y. Rubin, E. Majer, A. Ward, and G. Gee (2005), Estimation of field-scale soil hydraulic and dielectric parameters through joint inversion of GPR and hydrological data, Water Resour. Res., 41, W11425, doi:10.1029/2005WR004237.

Kumar, P. (1999), A multiple scale state-space model for characterizing subgrid scale variability of near-surface soil moisture, IEEE Trans. Geosci. Remote Sens., 37, 182-197, doi:10.1109/36.739153.

Kustas, W. P., and T. J. Jackson (1999), The impact on area-averaged heat fluxes from using remotely sensed data at different resolutions: A case study with Washita '92 data, Water Resour. Res., 35, 1539-1550, doi:10.1029/1998WR900122.

Laio, F., A. Porporato, L. Ridolfi, and I. Rodriguez-Iturbe (2002), On the seasonal dynamics of mean soil moisture, J. Geophys. Res., 107(D15), 4272, doi:10.1029/2001JD001252.

Lambot, S., and A. Gorriti (2007), Special issue on ground-penetrating radar-Foreword, Near Surf. Geophys., 5, 3-4.

Lambot, S., M. Javaux, F. Hupet, and M. Vanclooster (2002), A global multilevel coordinate search procedure for estimating the unsaturated soil hydraulic properties, Water Resour. Res., 38(11), 1224, doi:10.1029/ 2001WR001224

Lambot, S., F. Hupet, M. Javaux, and M. Vanclooster (2004), Laboratory evaluation of a hydrodynamic inverse modeling method based on water content data, Water Resour. Res., 40, W03506, doi:10.1029/ 2003 WR002641.

Lambot, S., E. C. Slob, M. Vanclooster, and H. Vereecken (2006a), Closed loop GPR data inversion for soil hydraulic and electric property determination, Geophys. Res. Lett., 33, L21405, doi:10.1029/2006GL027906.

Lambot, S., L. Weihermuller, J. A. Huisman, H. Vereecken, M. Vanclooster, and E. C. Slob (2006b), Analysis of air-launched ground-penetrating radar techniques to measure the soil surface water content, Water Resour. Res., 42, W11403, doi:10.1029/2006WR005097.

Laymon, C. A., et al. (1999), Huntsville'96: An experiment in groundbased microwave remote sensing of soil moisture, Int. J. Remote Sens., 20, 823-828, doi:10.1080/014311699213244.

Li, J., and S. Islam (1999), On the estimation of soil moisture profile and surface fluxes partitioning from sequential assimilation of surface layer soil moisture, J. Hydrol., 220, 86-103, doi:10.1016/S00221694(99)00066-9.

Li, Y., R. Wallach, and Y. Cohen (2002), The role of soil hydraulic conductivity on the spatial and temporal variation of root water uptake in drip-irrigated corn, Plant Soil, 243, 131-142, doi:10.1023/ A:1019911908635.

Lin, H. (2006), Temporal stability of soil moisture spatial pattern and subsurface preferential flow pathways in the shale hills catchment, Vadose Zone J., 5, 317-340, doi:10.2136/vzj2005.0058.

Lunt, I. A., S. S. Hubbard, and Y. Rubin (2005), Soil moisture content estimation using ground-penetrating radar reflection data, J. Hydrol., 307, 254-269, doi:10.1016/j.jhydrol.2004.10.014.

Mahmood, R. (1996), Scale issues in soil moisture modelling: Problems and prospects, Prog. Phys. Geogr., 20, 273-291, doi:10.1177/ 030913339602000302 .

Manfreda, S., and I. Rodríguez-Iturbe (2006), On the spatial and temporal sampling of soil moisture fields, Water Resour. Res., 42, W05409, doi:10.1029/2005WR004548.

Margulis, S. A., D. McLaughlin, D. Entekhabi, and S. Dunne (2002), Land data assimilation and estimation of soil moisture using measurements from the Southern Great Plains 1997 Field Experiment, Water Resour. Res., 38(12), 1299, doi:10.1029/2001WR001114.

Martinez-Fernandez, J., and A. Ceballos (2003), Temporal stability of soil moisture in a large-field experiment in Spain, Soil Sci. Soc. Am. J., 67, $1647-1656$.

Mattikalli, N. M., E. T. Engman, T. J. Jackson, and L. R. Ahuja (1998a), Microwave remote sensing of temporal variations of brightness temperature and near-surface soil water content during a watershed-scale field experiment, and its application to the estimation of soil physical properties, Water Resour. Res., 34, 2289-2299, doi:10.1029/98WR00553.

Mattikalli, N. M., E. T. Engman, L. R. Ahuja, and T. J. Jackson (1998b), Microwave remote sensing of soil moisture for estimation of profile soil property, Int. J. Remote Sens., 19, 1751-1767, doi:10.1080/ 014311698215234.

McLaughlin, D. B. (1978), Potential applications of Kalman filtering concepts to groundwater basin management, in Applications of Kalman Filter to Hydrology, Hydraulics, and Water Resources, edited by C.-L. Chiu, pp. 635-655, Univ. of Pittsburgh, Pittsburgh, Pa.

Merlin, O., A. Chehbouni, G. Boulet, and Y. Kerr (2006), Assimilation of disaggregated microwave soil moisture into a hydrologic model using coarse-scale meteorological data, J. Hydrometeorol., 7, 1308-1322, doi:10.1175/JHM552.1.

Mertens, J., H. Madsen, L. Feyen, D. Jacques, and J. Feyen (2004), Including prior information in the estimation of effective soil parameters in unsaturated zone modelling, J. Hydrol., 294, 251-269, doi:10.1016/ j.jhydrol.2004.02.011.

Mertens, J., H. Madsen, M. Kristensen, D. Jacques, and J. Feyen (2005), Sensitivity of soil parameters in unsaturated zone modelling and the relation between effective, laboratory and in situ estimates, Hydrol. Processes, 19, 1611-1633, doi:10.1002/hyp.5591.

Mertens, J., R. Stenger, and G. F. Barkle (2006), Multiobjective inverse modeling for soil parameter estimation and model verification, Vadose Zone J., 5, 917-933, doi:10.2136/vzj2005.0117.

Merz, B., and E. J. Plate (1997), An analysis of the effects of spatial variability of soil and soil moisture on runoff, Water Resour. Res., 33, 2909-2922, doi:10.1029/97WR02204.

Michot, D., Y. Benderitter, A. Dorigny, B. Nicoullaud, D. King, and A. Tabbagh (2003), Spatial and temporal monitoring of soil water content with an irrigated corn crop cover using surface electrical resistivity tomography, Water Resour. Res., 39(5), 1138, doi:10.1029/ 2002WR001581.

Mohanty, B. P., and T. H. Skaggs (2001), Spatio-temporal evolution and time-stable characteristics of soil moisture within remote sensing foot- 
prints with varying soil, slope, and vegetation, Adv. Water Resour., 24, 1051-1067, doi:10.1016/S0309-1708(01)00034-3.

Mohanty, B. P., T. H. Skaggs, and J. S. Famiglietti (2000), Analysis and mapping of field-scale soil moisture variability using high-resolution, ground-based data during the Southern Great Plains 1997 (SGP97) Hydrology Experiment, Water Resour. Res., 36, 1023-1031, doi:10.1029/1999WR900360.

Mohanty, B. P., P. J. Shouse, D. A. Miller, and M. T. van Genuchten (2002), Soil property database: Southern Great Plains 1997 Hydrology Experiment, Water Resour. Res., 38(5), 1047, doi:10.1029/2000WR000076.

Montaldo, N., and J. D. Albertson (2001), On the use of the force-restore SVAT model formulation for stratified soils, J. Hydrometeorol., 2, $571-$ 578, doi:10.1175/1525-7541(2001)002<0571:OTUOTF>2.0.CO;2.

Montaldo, N., and J. D. Albertson (2003a), Multi-scale assimilation of surface soil moisture data for robust root zone moisture predictions, Adv. Water Resour, 26, 33-44, doi:10.1016/S0309-1708(02)00103-3.

Montaldo, N., and J. D. Albertson (2003b), Temporal dynamics of soil moisture variability: 2. Implications for land surface models, Water Resour. Res., 39(10), 1275, doi:10.1029/2002WR001618.

Montaldo, N., J. D. Albertson, M. Mancini, and G. Kiely (2001), Robust simulation of root zone soil moisture with assimilation of surface soil moisture data, Water Resour. Res., 37, 2889-2900, doi:10.1029/ 2000WR000209.

Mori, Y., J. W. Hopmans, A. P. Mortensen, and G. J. Kluitenberg (2005), Estimation of vadose zone water flux from multi-functional heat pulse probe measurements, Soil Sci. Soc. Am. J., 69, 599-606, doi:10.2136/ sssaj2004.0174.

Mortensen, A. P., J. W. Hopmans, Y. Mori, and J. Simunek (2006), Multifunctional heat pulse probe measurements of coupled vadose zone flow and transport, Adv. Water Resour., 29, 250-267, doi:10.1016/ j.advwatres.2005.03.017.

Musters, P. A. D., and W. Bouten (1999), Assessing rooting depths of an Austrian pine stand by inverse modeling soil water content maps, Water Resour. Res., 35, 3041-3048, doi:10.1029/1999WR900173.

Musters, P. A. D., and W. Bouten (2000), A method for identifying optimum strategies of measuring soil water contents for calibrating a root water uptake model, J. Hydrol., 227, 273-286, doi:10.1016/S00221694(99)00187-0.

Musters, P. A. D., W. Bouten, and J. M. Verstraten (2000), Potentials and limitations of modelling vertical distributions of root water uptake of an Austrian pine forest on a sandy soil, Hydrol. Processes, 14, 103-115, doi:10.1002/(SICI)1099-1085(200001)14:1<103::AID-HYP913>3.0. $\mathrm{CO} ; 2-5$.

Narayan, U., V. Lakshmi, and E. G. Njoku (2004), Retrieval of soil moisture from passive and active L/S band sensor (PALS) observations during the Soil Moisture Experiment in 2002 (SMEX02), Remote Sens. Environ., 92, 483-496, doi:10.1016/j.rse.2004.05.018.

Nieber, J. L., and M. F. Walter (1981), Two-dimensional soil-moisture flow in a sloping rectangular region: Experimental and numerical studies, Water Resour. Res., 17, 1722-1730, doi:10.1029/WR017i006p01722.

Niemann, K. O., and M. C. R. Edgell (1993), Preliminary analysis of spatial and temporal distribution of soil moisture on a deforested slope, Phys. Geogr., 14, 449-464.

Ni-Meister, W., P. R. Houser, and J. P. Walker (2006), Soil moisture initialization for climate prediction: Assimilation of scanning multifrequency microwave radiometer soil moisture data into a land surface model, J. Geophys. Res., 111, D20102, doi:10.1029/2006JD007190.

Nutzmann, G., M. Thiele, S. Maciejewski, and K. Joswig (1998), Inverse modelling techniques for determining hydraulic properties of coarse-textured porous media by transient outflow methods, Adv. Water Resour., 22, 273-284, doi:10.1016/S0309-1708(98)00009-8.

Oldak, A., T. J. Jackson, and Y. Pachepsky (2002), Using GIS in passive microwave soil moisture mapping and geostatistical analysis, Int. J. Geogr. Inf. Sci., 16, 681-698, doi:10.1080/13658810210149407.

Or, D., and R. J. Hanks (1992), Spatial and temporal soil water estimation considering soil variability and evapotranspiration uncertainty, Water Resour. Res., 28, 803-814, doi:10.1029/91WR02585.

Owe, M., E. B. Jones, and T. J. Schmugge (1982), Soil-moisture variation patterns observed in Hand County, South Dakota, Water Resour. Bull., 18, 949-954.

Pachepsky, Y. A., A. K. Guber, and D. Jacques (2005), Temporal persistence in vertical distributions of soil moisture contents, Soil Sci. Soc. Am. J., 69, 347-352.

Pan, L. H., and L. S. Wu (1998), A hybrid global optimization method for inverse estimation of hydraulic parameters: Annealing-simplex method, Water Resour. Res., 34, 2261-2269, doi:10.1029/98WR01672.
Pan, M., and E. F. Wood (2006), Data assimilation for estimating the terrestrial water budget using a constrained ensemble Kalman filter, J. Hydrometeorol., 7, 534-547, doi:10.1175/JHM495.1.

Paniconi, C., M. Marrocu, M. Putti, and M. Verbunt (2003), Newtonian nudging for a Richards equation-based distributed hydrological model, Adv. Water Resour., 26, 161-178, doi:10.1016/S0309-1708(02)00099-4.

Parada, L. M., and X. Liang (2004), Optimal multiscale Kalman filter for assimilation of near-surface soil moisture into land surface models, J. Geophys. Res., 109, D24109, doi:10.1029/2004JD004745.

Parajka, J., V. Naeimi, G. Blöschl, W. Wagner, R. Merz, and K. Scipal (2006), Assimilating scatterometer soil moisture data into conceptual hydrologic models at the regional scale, Hydrol. Earth Syst. Sci., 10, 353-368.

Pariente, S. (2002), Spatial patterns of soil moisture as affected by shrubs, in different climatic conditions, Environ. Monit. Assess., 73, 237-251, doi:10.1023/A:1013119405441.

Pauwels, V. R. N., R. Hoeben, N. E. C. Verhoest, and F. P. De Troch (2001), The importance of the spatial patterns of remotely sensed soil moisture in the improvement of discharge predictions for small-scale basins through data assimilation, J. Hydrol., 251, 88-102, doi:10.1016/S00221694(01)00440-1.

Pauwels, V. R. N., R. Hoeben, N. E. C. Verhoest, F. P. De Troch, and P. A. Troech (2002), Improvement of TOPLATS-based discharge predictions through assimilation of ERS-based remotely sensed soil moisture values, Hydrol. Processes, 16, 995-1013, doi:10.1002/hyp.315.

Pauwels, V. R. N., N. E. C. Verhoest, G. J. M. De Lannoy, V. Guissard, C. Lucau, and P. Defourny (2007), Optimization of a coupled hydrology-crop growth model through the assimilation of observed soil moisture and leaf area index values using an ensemble Kalman filter, Water Resour. Res., 43, W04421, doi:10.1029/2006WR004942.

Perry, M. A., and J. D. Niemann (2007), Analysis and estimation of soil moisture at the catchment scale using EOFs, J. Hydrol., 334, 388-404, doi:10.1016/j.jhydrol.2006.10.014.

Pratt, D. A., and C. D. Ellyett (1979), Thermal inertia approach to mapping of soil moisture and geology, Remote Sens. Environ., 8, 151-168, doi:10.1016/0034-4257(79)90014-2.

Prevot, L., R. Bernard, O. Taconet, D. Vidalmadjar, and J. L. Thony (1984), Evaporation from a bare soil evaluated using a soil-water transfer model and remotely sensed surface soil moisture data, Water Resour. Res., 20, 311-316, doi:10.1029/WR020i002p00311.

Price, J. C. (1980), The potential of remotely sensed thermal infrared data to infer surface soil moisture and evaporation, Water Resour. Res., 16, $787-$ 795, doi:10.1029/WR016i004p00787.

Reggiani, P., M. Sivapalan, and S. M. Hassanizadeh (2000), Conservation equations governing hillslope responses: Exploring the physical basis of water balance, Water Resour. Res., 36, 1845-1863, doi:10.1029/ 2000WR900066.

Reichle, R. (2008), Data assimilation methods in the Earth sciences, $A d v$. Water Resour, in press.

Reichle, R. H., D. B. McLaughlin, and D. Entekhabi (2001), Variational data assimilation of microwave radiobrightness observations for land surface hydrology applications, IEEE Trans. Geosci. Remote Sens., 39, 1708-1718, doi:10.1109/36.942549.

Reichle, R. H., J. P. Walker, R. D. Koster, and P. R. Houser (2002a), Extended versus ensemble Kalman filtering for land data assimilation, J. Hydrometeorol., 3, 728-740, doi:10.1175/1525-7541(2002)003< 0728:EVEKFF>2.0.CO;2.

Reichle, R. H., D. B. McLaughlin, and D. Entekhabi (2002a), Hydrologic data assimilation with the ensemble Kalman filter, Mon. Weather Rev, 130, 103-114, doi:10.1175/1520-0493(2002)130<0103:HDAWTE> 2.0.CO;2.

Reid, I. (1973), The influence of slope orientation upon the soil moisture regime and its hydrogeomorphologcial significance, J. Hydrol., 19, 309321, doi:10.1016/0022-1694(73)90105-4.

Ren, T., G. J. Kluitenberg, and R. Horton (2000), Determining soil water flux and pore water velocity by a heat pulse technique, Soil Sci. Soc. Am. $J ., 64,552-560$.

Retter, M., P. Kienzler, and P. F. Germann (2006), Vectors of subsurface stormflow in a layered hillslope during runoff initiation, Hydrol. Earth Syst. Sci., 10, 309-320.

Ridolfi, L., P. D’Odorico, A. Porporato, and I. Rodriguez-Iturbe (2003), Stochastic soil moisture dynamics along a hillslope, J. Hydrol., 272, 264-275, doi:10.1016/S0022-1694(02)00270-6.

Ritter, A., F. Hupet, R. Munoz-Carpena, S. Lambot, and M. Vanclooster (2003), Using inverse methods for estimating soil hydraulic properties 
from field data as an alternative to direct methods, Agric. Water Manage., 59, 77-96, doi:10.1016/S0378-3774(02)00160-9.

Robinson, D. A., S. B. Jones, J. A. Wraith, D. Or, and S. P. Friedman (2003), A review of advances in dielectric and electrical conductivity measurement in soils using time domain reflectometry, Vadose Zone J., 2 , 444-475.

Robinson, D. A., C. S. Campbell, J. W. Hopmans, B. K. Hornbuckle, S. B. Jones, R. Knight, F. Ogden, J. Selker, and O. Wendroth (2008), Soil moisture measurements for ecological and hydrological watershed scale observatories: A review, Vadose Zone J., 7, 358-389, doi:10.2136/ vzj2007.0143.

Robock, A., K. Y. Vinnikov, G. Srinivasan, J. K. Entin, S. E. Hollinger, N. A. Speranskaya, S. X. Liu, and A. Namkhai (2000), The Global Soil Moisture Data Bank, Bull. Am. Meteorol. Soc., 81, 1281-1299, doi:10.1175/1520-0477(2000)081<1281:TGSMDB>2.3.CO;2.

Rodriguez-Iturbe, I., G. K. Vogel, R. Rigon, D. Entekhabi, F. Castelli, and A. Rinaldo (1995), On the spatial organization of soil moisture fields, Geophys. Res. Lett., 22, 2757-2760, doi:10.1029/95GL02779.

Rodriguez-Iturbe, I., A. Porporato, L. Ridolfi, V. Isham, and D. R. Cox (1999), Probabilistic modelling of water balance at a point: The role of climate, soil and vegetation, Proc. R. Soc. London, Ser. A, 455, 37893805 .

Rodriguez-Iturbe, I., V. Isham, D. R. Cox, S. Manfreda, and A. Porporato (2006), Space-time modeling of soil moisture: Stochastic rainfall forcing with heterogeneous vegetation, Water Resour. Res., 42, W06D05, doi:10.1029/2005WR004497.

Ross, P. J. (1993), A method of deriving soil hydraulic properties from field water contents for application in water-balance studies, J. Hydrol., 144, 143-153, doi:10.1016/0022-1694(93)90169-A.

Rubin, Y., and S. S. Hubbard (2005), Hydrogeophysics, Water Sci. Technol. Libr., vol. 50, 523 pp., Springer, Dordrecht, Netherlands.

Rucker, D. F., and T. P. A. Ferré (2004), Parameter estimation for soil hydraulic properties using zero-offset borehole radar: Analytical method, Soil Sci. Soc. Am. J., 68, 1560-1567.

Rushton, K. R., V. H. M. Eilers, and R. C. Carter (2006), Improved soil moisture balance methodology for recharge estimation, J. Hydrol., 318, 379-399, doi:10.1016/j.jhydrol.2005.06.022.

Ryu, D., and J. S. Famiglietti (2005), Characterization of footprint-scale surface soil moisture variability using Gaussian and beta distribution functions during the Southern Great Plains 1997 (SGP97) hydrology experiment, Water Resour. Res., 41, W12433, doi:10.1029/ 2004WR003835.

Sabater, J. M., L. Jarlan, J. C. Calvet, F. Bouyssel, and P. De Rosnay (2007), From near-surface to root-zone soil moisture using different assimilation techniques, J. Hydrometeorol., 8, 194-206, doi:10.1175/ JHM571.1

Samouelian, A., I. Cousin, A. Tabbagh, A. Bruand, and G. Richard (2005), Electrical resistivity survey in soil science: A review, Soil Tillage Res., 83, 173-193, doi:10.1016/j.still.2004.10.004.

Satalino, G., F. Mattia, M. W. J. Davidson, T. Le Toan, G. Pasquariello, and M. Borgeaud (2002), On current limits of soil moisture retrieval from ERS-SAR data, IEEE Trans. Geosci. Remote Sens., 40, 2438-2447, doi:10.1109/TGRS.2002.803790.

Schmugge, T. (1998), Applications of passive microwave observations of surface soil moisture, J. Hydrol., 212-213, 188-197, doi:10.1016/ S0022-1694(98)00209-1.

Schmugge, T., T. J. Jackson, W. P. Kustas, and J. R. Wang (1992), Passive microwave remote sensing of soil moisture-Results from Hapex, Fife and Monsoon-90, ISPRS J. Photogramm. Remote Sens., 47, 127-143, doi:10.1016/0924-2716(92)90029-9.

Schmugge, T. J., W. P. Kustas, J. C. Ritchie, T. J. Jackson, and A. Rango (2002), Remote sensing in hydrology, Adv. Water Resour., 25, $1367-$ 1385, doi:10.1016/S0309-1708(02)00065-9.

Schoups, G., J. W. Hopmans, C. A. Young, J. A. Vrugt, and W. W. Wallender (2005a), Multi-criteria optimization of a regional spatially-distributed subsurface water flow model, J. Hydrol., 311, 20-48, doi:10.1016/ j.jhydrol.2005.01.001.

Schoups, G., J. W. Hopmans, C. A. Young, J. A. Vrugt, W. W. Wallender, K. K. Tanji, and S. Panday (2005b), Sustainability of irrigated agriculture in the San Joaquin Valley, California, Proc. Natl. Acad. Sci. U. S. A., 102, 15,352-15,356, doi:10.1073/pnas.0507723102.

Scipal, K., C. Scheffler, and W. Wagner (2005), Soil moisture-runoff relation at the catchment scale as observed with coarse resolution microwave remote sensing, Hydrol. Earth Syst. Sci., 9, 173-183.

Scott, R. L., W. J. Shuttleworth, T. O. Keefer, and A. W. Warrick (2000), Modeling multiyear observations of soil moisture recharge in the semi- arid American Southwest, Water Resour. Res., 36, 2233-2247, doi:10.1029/2000WR900116.

Sellers, P. J., F. G. Hall, G. Asrar, D. E. Strebel, and R. E. Murphy (1992), An overview of the 1st International Satellite Land Surface Climatology Project (ISLSCP) Field Experiment (FIFE), J. Geophys. Res., 97, $18,345-18,371$.

Sellers, P. J., M. D. Heiser, F. G. Hall, S. J. Goetz, D. E. Strebel, S. B. Verma, R. L. Desjardins, P. M. Schuepp, and J. I. MacPherson (1995), Effects of spatial variability in topography, vegetation cover and soil moisture on area-averaged surface fluxes: A case study using the FIFE 1989 data, J. Geophys. Res., 100, 25,607-25,629, doi:10.1029/ 95JD02205.

Serbin, G., and D. Or (2004), Ground-penetrating radar measurement of soil water content dynamics using a suspended horn antenna, IEEE Trans. Geosci. Remote Sens., 42, 1695-1705, doi:10.1109/ TGRS.2004.831693.

Serbin, G., and D. Or (2005), Ground-penetrating radar measurement of crop and surface water content dynamics, Remote Sens. Environ., 96, 119-134, doi:10.1016/j.rse.2005.01.018.

Settin, T., G. Botter, I. Rodriguez-Iturbe, and A. Rinaldo (2007), Numerical studies on soil moisture distributions in heterogeneous catchments, Water Resour. Res., 43, W05425, doi:10.1029/2006WR005737.

Sheets, K. R., and J. M. H. Hendrickx (1995), Noninvasive soil-water content measurement using electromagnetic induction, Water Resour. Res., 31, 2401-2409, doi:10.1029/95WR01949.

Si, B. C., and R. G. Kachanoski (2000), Estimating soil hydraulic properties during constant flux infiltration: Inverse procedures, Soil Sci. Soc. Am. J., 64, 439-449.

Simunek, J., and J. W. Hopmans (2002), Parameter optimization and nonlinear fitting, in Methods of Soil Analyses, edited by J. H. Dane and G. C. Topp, pp. 139-158, Soil. Sci. Soc. of Am., Madison, Wis.

Simunek, J., O. Wendroth, and M. T. van Genuchten (1998), Parameter estimation analysis of the evaporation method for determining soil hydraulic properties, Soil Sci. Soc. Am. J., 62, 894-905.

Sisson, J. B., and M. T. van Genuchten (1991), An improved analysis of gravity-drainage experiments for estimating the unsaturated soil hydraulic properties, Water Resour. Res., 27, 569-575, doi:10.1029/ 91WR00184.

Sposito, G. (1998), Scale Dependence and Scale Invariance in Hydrology, 423 pp., Cambridge Univ. Press, Cambridge, U. K.

Starks, P. J., G. C. Heathman, T. J. Jackson, and M. H. Cosh (2006), Temporal stability of soil moisture profile, J. Hydrol., 324, 400-411, doi:10.1016/j.jhydrol.2005.09.024.

Starr, G. C. (2005), Assessing temporal stability and spatial variability of soil water patterns with implications for precision water management, Agric. Water Manage., 72, 223-243, doi:10.1016/j.agwat.2004.09.020.

Sugiura, R., N. Noguchi, and K. Ishii (2007), Correction of low-altitude thermal images applied to estimating soil water status, Biosyst. Eng., 96, 301-313, doi:10.1016/j.biosystemseng.2006.11.006.

Takeshita, Y. (1999), Parameter estimation of unsaturated soil hydraulic properties from transient outflow experiments using genetic algorithms, paper presented at Characterization and Measurement of the Hydraulic Properties of Unsaturated Porous Media, U.S. Salinity Lab., Agric. Res. Serv., U.S. Dep. of Agric., Riverside, Calif., 22-24 Oct.

Teuling, A. J., R. Uijlenhoet, F. Hupet, E. E. van Loon, and P. A. Troch (2006), Estimating spatial mean root-zone soil moisture from point-scale observations, Hydrol. Earth Syst. Sci., 10, 755-767.

Teuling, A. J., F. Hupet, R. Uijlenhoet, and P. A. Troch (2007), Climate variability effects on spatial soil moisture dynamics, Geophys. Res. Lett., 34, L06406, doi:10.1029/2006GL029080.

Thierfelder, T. K., R. B. Grayson, D. von Rosen, and A. W. Western (2003), Inferring the location of catchment characteristic soil moisture monitoring sites. Covariance structures in the temporal domain, J. Hydrol., 280, 13-32, doi:10.1016/S0022-1694(03)00077-5.

Topp, G. C. (2003), State of the art of measuring soil water content, Hydrol. Processes, 17, 2993-2996, doi:10.1002/hyp.5148.

Tromp-van Meerveld, H. J., and J. J. McDonnell (2006), On the interrelations between topography, soil depth, soil moisture, transpiration rates and species distribution at the hillslope scale, Adv. Water Resour., 29, 293-310, doi:10.1016/j.advwatres.2005.02.016.

Ulaby, F. T., P. C. Dubois, and J. van Zyl (1996), Radar mapping of surface soil moisture, J. Hydrol., 184, 57-84, doi:10.1016/00221694(95)02968-0.

Vachaud, G., A. P. Desilans, P. Balabanis, and M. Vauclin (1985), Temporal stability of spatially measured soil-water probability density function, Soil Sci. Soc. Am. J., 49, 822-828. 
Valente, A., R. Morais, A. Tuli, J. W. Hopmans, and G. J. Kluitenberg (2006), Multi-functional probe for small-scale simultaneous measurements of soil thermal properties, water content, and electrical conductivity, Sensors Actuators A, 132, 70-77, doi:10.1016/j.sna.2006.05.010.

van Dam, J. C., J. N. M. Stricker, and P. Droogers (1992), Inverse method for determining soil hydraulic functions from one-step outflow experiments, Soil Sci. Soc. Am. J., 56, 1042-1050.

van Groenigen, J. W. (2000), The influence of variogram parameters on optimal sampling schemes for mapping by kriging, Geoderma, 97, 223236.

Vereecken, H., M. Vanclooster, M. Swerts, and J. Diels (1991), Simulating water and nitrogen behaviour in soils cropped with winter wheat, Nutrient Cycling Agroecosyst., 27, 233-243, doi:10.1007/BF01051130.

Vereecken, H., R. Kaiser, M. Dust, and T. Putz (1997), Evaluations of the multistep outflow method for the determination of unsaturated hydraulic properties of soils, Soil Sci., 162, 618-631, doi:10.1097/00010694199709000-00003.

Vereecken, H., S. Hubbard, A. Binley, and T. Ferré (2004), Hydrogeophysics: An introduction from the guest editors, Vadose Zone J., 3, $1060-$ 1062.

Vereecken, H., A. Binley, G. Cassiani, A. Revil, and K. Titov (2006), Applied Hydrogeophysics, NATO Sci Ser. Ser. 4, vol. 71, 383 pp., Springer, Dordrecht, Netherlands.

Vereecken, H., R. Kasteel, J. Vanderborght, and T. Harter (2007a), Upscaling hydraulic properties and soil water flow processes in heterogeneous soils: A review, Vadose Zone J., 6, 1-28, doi:10.2136/vzj2006.0055.

Vereecken, H., T. Kamai, T. Harter, R. Kasteel, J. Hopmans, and J. Vanderborght (2007b), Explaining soil moisture variability as a function of mean soil moisture: A stochastic unsaturated flow perspective, Geophys. Res. Lett., 34, L22402, doi:10.1029/2007GL031813.

Verhoest, N. E. C., P. A. Troch, C. Paniconi, and F. P. De Troch (1998), Mapping basin scale variable source areas from multitemporal remotely sensed observations of soil moisture behavior, Water Resour. Res., 34, 3235-3244, doi:10.1029/98WR02046.

Verhoest, N. E. C., B. De Baets, and H. Vernieuwe (2007), A TakagiSugeno fuzzy rule-based model for soil moisture retrieval from SAR under soil roughness uncertainty, IEEE Trans. Geosci. Remote Sens., 45, 1351-1360, doi:10.1109/TGRS.2007.894930.

Verstraeten, W. W., F. Veroustraete, C. J. van der Sande, I. Grootaers, and J. Feyen (2006), Soil moisture retrieval using thermal inertia, determined with visible and thermal spaceborne data, validated for European forests, Remote Sens. Environ., 101, 299-314, doi:10.1016/j.rse. 2005.12.016.

Visser, A., R. Stuurman, and M. F. P. Bierkens (2006), Real-time forecasting of water table depth and soil moisture profiles, Adv. Water Resour., 29, 692-706, doi:10.1016/j.advwatres.2005.07.011.

Vogeler, I., S. R. Green, D. R. Scotter, and B. E. Clothier (2001), Measuring and modelling the transport and root uptake of chemicals in the unsaturated zone, Plant Soil, 231, 161-174, doi:10.1023/A:1010337132309.

Vrugt, J. A., and W. Bouten (2002), Validity of first-order approximations to describe parameter uncertainty in soil hydrologic models, Soil Sci. Soc. Am. J., 66, 1740-1751.

Vrugt, J. A., and J. H. Dane (2005), Inverse modeling of soil hydraulic properties, in Encyclopedia of Hydrological Sciences, edited by M. G. Anderson, pp. 1103-1120, John Wiley, Chichester, U. K.

Vrugt, J. A., and B. A. Robinson (2007), Improved evolutionary optimization from genetically adaptive multimethod search, Proc. Natl. Acad. Sci. U. S. A., 104, 708-711, doi:10.1073/pnas.0610471104.

Vrugt, J. A., W. Bouten, and A. H. Weerts (2001a), Information content of data for identifying soil hydraulic parameters from outflow experiments, Soil Sci. Soc. Am. J., 65, 19-27.

Vrugt, J. A., J. W. Hopmans, and J. Simunek (2001b), Calibration of a twodimensional root water uptake model, Soil Sci. Soc. Am. J., 65, $1027-$ 1037.

Vrugt, J. A., M. T. van Wijk, J. W. Hopmans, and J. Simunek (2001c), One-, two-, and three-dimensional root water uptake functions for transient modeling, Water Resour. Res., 37, 2457-2470, doi:10.1029/ 2000WR000027.

Vrugt, J. A., H. V. Gupta, L. A. Bastidas, W. Bouten, and S. Sorooshian (2003), Effective and efficient algorithm for multiobjective optimization of hydrologic models, Water Resour. Res., 39(8), 1214, doi:10.1029/ 2002 WR001746.

Vrugt, J. A., G. Schoups, J. W. Hopmans, C. Young, W. W. Wallender, T. Harter, and W. Bouten (2004), Inverse modeling of large-scale spatially distributed vadose zone properties using global optimization, Water Resour. Res., 40, W06503, doi:10.1029/2003WR002706.
Wagner, W., K. Scipal, C. Pathe, D. Gerten, W. Lucht, and B. Rudolf (2003), Evaluation of the agreement between the first global remotely sensed soil moisture data with model and precipitation data, J. Geophys. Res., 108(D19), 4611, doi:10.1029/2003JD003663.

Wagner, W., G. Blöschl, P. Pampaloni, J. C. Calvet, B. Bizzarri, J. P. Wigneron, and Y. Kerr (2007), Operational readiness of microwave remote sensing of soil moisture for hydrologic applications, Nord. Hydrol., 38, 1-20, doi:10.2166/nh.2007.029.

Walker, J. P., G. R. Willgoose, and J. D. Kalma (2001a), One-dimensional soil moisture profile retrieval by assimilation of near-surface measurements: A simplified soil moisture model and field application, J. Hydrometeorol., 2, 356-373, doi:10.1175/1525-7541(2001)002<0356: ODSMPR $>2.0 . \mathrm{CO} ; 2$.

Walker, J. P., G. R. Willgoose, and J. D. Kalma (2001b), One-dimensional soil moisture profile retrieval by assimilation of near-surface observations: A comparison of retrieval algorithms, Adv. Water Resour., 24, 631-650, doi:10.1016/S0309-1708(00)00043-9.

Walker, J. P., G. R. Willgoose, and J. D. Kalma (2002), Three-dimensional soil moisture profile retrieval by assimilation of near-surface measurements: Simplified Kalman filter covariance forecasting and field application, Water Resour. Res., 38(12), 1301, doi:10.1029/2002WR001545.

Ward, A. L., Z. F. Zhang, and G. W. Gee (2006), Upscaling unsaturated hydraulic parameters for flow through heterogeneous anisotropic sediments, Adv. Water Resour., 29, 268-280, doi:10.1016/j.advwatres. 2005.02.013.

Wendroth, O., G. G. Katul, M. B. Parlange, C. E. Puente, and D. R. Nielsen (1993), A nonlinear filtering approach for determining hydraulic conductivity functions in field soils, Soil Sci., 156, 293-301, doi:10.1097/ 00010694-199311000-00001.

Wendroth, O., W. Pohl, S. Koszinski, H. Rogasik, C. J. Ritsema, and D. R. Nielsen (1999a), Spatio-temporal patterns and covariance structures of soil water status in two northeast German field sites, J. Hydrol., 215, 3858, doi:10.1016/S0022-1694(98)00260-1.

Wendroth, O., H. Rogasik, S. Koszinski, C. J. Ritsema, L. W. Dekker, and D. R. Nielsen (1999b), State-space prediction of field-scale soil water content time series in a sandy loam, Soil Tillage Res., 50, 85-93, doi:10.1016/S0167-1987(98)00201-3.

Western, A. W., and G. Blöschl (1999), On the spatial scaling of soil moisture, J. Hydrol., 217, 203-224, doi:10.1016/S00221694(98)00232-7.

Western, A. W., and R. B. Grayson (1998), The Tarrawarra data set: Soil moisture patterns, soil characteristics, and hydrological flux measurements, Water Resour. Res., 34, 2765-2768, doi:10.1029/98WR01833.

Western, A. W., R. B. Grayson, G. Blöschl, G. R. Willgoose, and T. A. McMahon (1999), Observed spatial organization of soil moisture and its relation to terrain indices, Water Resour. Res., 35, 797-810, doi:10.1029/ 1998WR900065.

Western, A. W., R. B. Grayson, and G. Blöschl (2002), Scaling of soil moisture: A hydrologic perspective, Annu. Rev. Earth Planet. Sci., 30, 149-180, doi:10.1146/annurev.earth.30.091201.140434.

Western, A. W., S. L. Zhou, R. B. Grayson, T. A. McMahon, G. Blöschl, and D. J. Wilson (2004), Spatial correlation of soil moisture in small catchments and its relationship to dominant spatial hydrological processes, J. Hydrol., 286, 113-134, doi:10.1016/j.jhydrol.2003.09.014.

Wetzel, P. J., and J. T. Chang (1987), Concerning the relationship between evapotranspiration and soil moisture, J. Clim. Appl. Meteorol., 26, $18-$ 27, doi:10.1175/1520-0450(1987)026<0018:CTRBEA>2.0.CO;2.

Wilson, D. J., A. W. Western, and R. B. Grayson (2005), A terrain and databased method for generating the spatial distribution of soil moisture, $A d v$. Water Resour, 28, 43-54, doi:10.1016/j.advwatres.2004.09.007.

Wilson, R. C., R. S. Freeland, J. B. Wilkerson, and R. E. Yoder (2003), Inferring subsurface morphology from transient soil moisture patterns using electrical conductivity, Trans. ASAE, 46, 1435-1441.

Wöhling, T., J. A. Vrugt, and G. F. Barkle (2008), Comparison of three multiobjective optimization algorithms for inverse modeling of vadose zone hydraulic properties, Soil Sci. Soc. Am. J., 72, 305-319, doi:10.2136/sssaj2007.0176.

Ye, M., R. Khaleel, and T. C. J. Yeh (2005), Stochastic analysis of moisture plume dynamics of a field injection experiment, Water Resour. Res., 41, W03013, doi:10.1029/2004WR003735.

Yeh, T. C. J., M. Ye, and R. Khaleel (2005), Estimation of effective unsaturated hydraulic conductivity tensor using spatial moments of observed moisture plume, Water Resour. Res., 41, W03014, doi:10.1029/2004WR003736.

Yeh, W. W. G. (1986), Review of parameter identification procedures in groundwater hydrology: The inverse problem, Water Resour. Res., 22, 95-108, doi:10.1029/WR022i002p00095. 
Yoo, C. (2001), Sampling of soil moisture fields and related errors: Implications to the optimal sampling design, Adv. Water Resour, 24, 521530, doi:10.1016/S0309-1708(00)00033-6.

Zhou, Q. Y., J. Shimada, and A. Sato (2001), Three-dimensional spatial and temporal monitoring of soil water content using electrical resistivity tomography, Water Resour. Res., 37, 273-285, doi:10.1029/ 2000WR900284.

H. Bogena, J. A. Huisman, J. Vanderborght, and H. Vereecken, Agrosphere Institute, ICG-4, Institute of Chemistry and Dynamics of the Geosphere, Forschungszentrum Jülich GmbH, D-52485 Jülich, Germany. (h.vereecken@fz-juelich.de)

J. W. Hopmans, Department of Land, Air and Water Resources, University of California, 123 Veihmeyer Hall, Davis, CA 95616-8628, USA.

J. A. Vrugt, Center for Nonlinear Studies, Los Alamos National Laboratory, Mail Stop B258, Los Alamos, NM 87545, USA. 